AROUEOLOGÍA Y SOCIEDAD № $25,2012: 143^{-1} 68$

ISSN: 0254-8062

RECIBIDO:JULIO DE 2012

ACEPTADO: OCTUBRE DE 2012

\title{
ASENTAMIENTOS PERIFÉRICOS DEL CENTRO URBANO DE CONCHOPATA, AYACUCHO
}

\author{
ISMAEL PÉREZ CALDERÓN \\ Universidad Nacional de SAN CRISTÓbAL DE HuAMANGA, FACULTAd de CiEnCIAS SOCIALES \\ zismaelunsch@hotmail.com
}

\section{RESUMEN}

Se presenta información sobre una variedad de restos arqueológicos ubicados en la periferia del centro urbano de Conchopata en Ayacucho, con lo que se demuestra no solo una larga ocupación sino un patrón urbano con antecedentes en culturas locales previas a la cultura Wari. Se tiene registrado más de 200 asentamientos distribuidos entre los 2500 y $4250 \mathrm{msnm}$, cuyos antiguos pobladores aprovecharon al máximo los recursos naturales de la zona así como el dominio del espacio geográfico, entre las evidencias destacan canteras, andenes, canales, reservorios, qochas, manantiales, centros poblados, arte rupestre, cuevas, adoratorios, huancas, ushnos, caminos, etc., dispersos en la cima de cerros, abras, montículos, laderas, planicies y profundidades de las quebradas que integran el curso superior de la cuenca del Huarpa en sierra sur central de los Andes peruanos.

Palabras clave: Asentamientos, periferia, secuencia cultural, Conchopata.

\begin{abstract}
Provides information on a variety of archaeological remains on the periphery of downtown Conchopata in Ayacucho, which is demonstrated not only a long occupation but an urban pattern with a background in local cultures prior to the Wari culture. He has logged more than 200 settlements distributed between 2500 and 4250 masl, whose ancient people made the most of natural resources in the area as well as the domain of geographic space, between the evidence include quarries, docks, canals, reservoirs, qochas, springs, settlements, rock art, caves, temples, huancas, ushnos, roads, etc., scattered on top of hills, creeks, hills, slopes, plains and deep gorges that make up the upper basin in southern highlands Huarpa central Peruvian Andes.
\end{abstract}

KEYwORDS: Settlements, periphery, cultural sequence, Conchopata.

\section{INTRODUCCIÓN}

La información que se presenta corresponde al registro y evaluación de un conjunto de restos arqueológicos dispersos en la periferia del asentamiento arqueológico Wari de Conchopata, distrito de Ayacucho, provincia de Huamanga, ámbito territorial que cuenta con abundante información a lo que se agrega el reconocimiento directo de nuevos sitios que corrobora la secuencia cultural que se inicia 
en la cueva Puente y prosigue hasta la ocupación incaica. En esta etapa del desarrollo de la investigación se han confeccionado planos con distribución de sitios, así como la formación de un archivo fotográfico, algunos materiales han sido recolectados, pero forman parte de un posterior estudio, por ahora solo se ha rotulado y clasificado. Nuestro objetivo es dar a conocer para entender de manera integral el funcionamiento del sitio arqueológico de Conchopata, para lo cual se han recorrido las microcuencas de los ríos Viñaca, Chillico, Huatatas y Yucaes, llegando por la parte baja hasta los valles de la Compañía y Pongora y por la parte alta hasta las alturas de Chiara,

Son más de doscientos los sitios registrados, en un mayor porcentaje corresponden a las fase Huarpa, seguidos de Ocros y Wari, y en menor proporción a las fases: Puente, Jaywa, Piki, Cachi, Andamarca, Wichqana, Chupas, Rancha, así como a las fases tardías de relacionadas con las Chanka e Inca. Los restos registrados han sido agrupados en las categorías de: Asentamientos poblacionales, reservorios, fortificaciones, caminos, andenerías, fuentes de agua, canteras, entre otros, con materiales asociados cuyo estudio preliminar permite corroborar las inferencias planteadas en torno a la secuencia cultural y patrón de asentamiento, propuesta por Mac Neish et al. (1981).

\section{INVESTIGACIONES PREVIAS}

De manera particular el asentamiento de Conchopata y alrededores han sido objeto de diferentes investigaciones, en la etapa de la arqueología científica destacan los trabajos pioneros de Julio C. Tello (1931/1969) posteriormente Rowe et.al. (1949), Bennett (1953), Lumbreras (1958, 1959, 1960, 1969, 1974), Casafranca (1960), Flores (1960), Benavides (1976), Mac Neish et al. (1981, 1983). Isbell (1985, 2001, 2009), Pozzi Escot $(1982,1985,1991,2009)$, Ochatoma $(1985,1986,1987,2007)$, Ochatoma y Cabrera (2001), Cabrera (1991), Machaca (1991, 1997), Alarcón (1991), Berrocal (1991), Alarcón (1999), Pérez (1998, 2003), Pérez y Ochatoma (1992, 1998), Cárdenas (1995), Tapahuasco (1993), Marroquín (2004), Ortega (2006), Paucar (2005), Mancilla (2008), Verástegui (2009) a los que se incluye cerca de medio centenar de trabajos entre informes de prácticas de estudiantes de la Universidad San Cristóbal de Huamanga y tesis de arqueólogos peruanos y extranjeros.

\section{Metodología y TÉCNICAS}

Para la recolección de datos seguimos el convencional método de reconocimiento directo que consistió en localizar y documentar en el propio espacio geográfico los restos de cultura material visibles a nivel de superficie, los mismos que fueron ubicados en la carta nacional 27ñ de Ayacucho, para su contraste con la distribución de sitios por Benavides (1976); Mac Neish et al. (1981). La localización de los sitios se hizo recorriendo a pie las diferentes partes de los valles a partir del poblado actual más cercano hasta donde se llegó utilizando movilidad. Algunos de los sitios fueron registrados con el apoyo de pobladores del lugar, caso de la zona de Tambillo y Huascahura.

El área fue dividida en cuatro zonas: noroeste, noreste, sureste y suroeste, iniciamos prospectando en el primero hasta culminar en la zona suroeste (Fig. 1), luego de manera deductiva tratamos de generalizar la información explicando el proceso cultural desde el Precerámico con la fase Puente (9000-7000 a.C.) hasta la época Inka. En la búsqueda de datos utilizamos la carta nacional, complementados con diferentes croquis de cada lugar, en el acopio de datos empleamos una ficha impresa que comprende: Nombre del sitio, ubicación política y geográfica, accesibilidad, clase de resto, descripción general, materiales asociados a la superficie, muestras recolectadas, restos cercanos de relación cultural, recursos naturales del lugar, investigaciones previas y comentario sobre la posible función. El registro incluye la documentación fotográfica, todo lo cual ha permitido ampliar el conocimiento de la arqueología regional de Ayacucho. Hay algunos sitios arqueológicos que están siendo deteriorados por labores agrícolas, construcción de caminos, carreteras, viviendas, instalaciones de postes de electrificación, construcción de canales y otras obras de infraestructura social y económica de la región. 


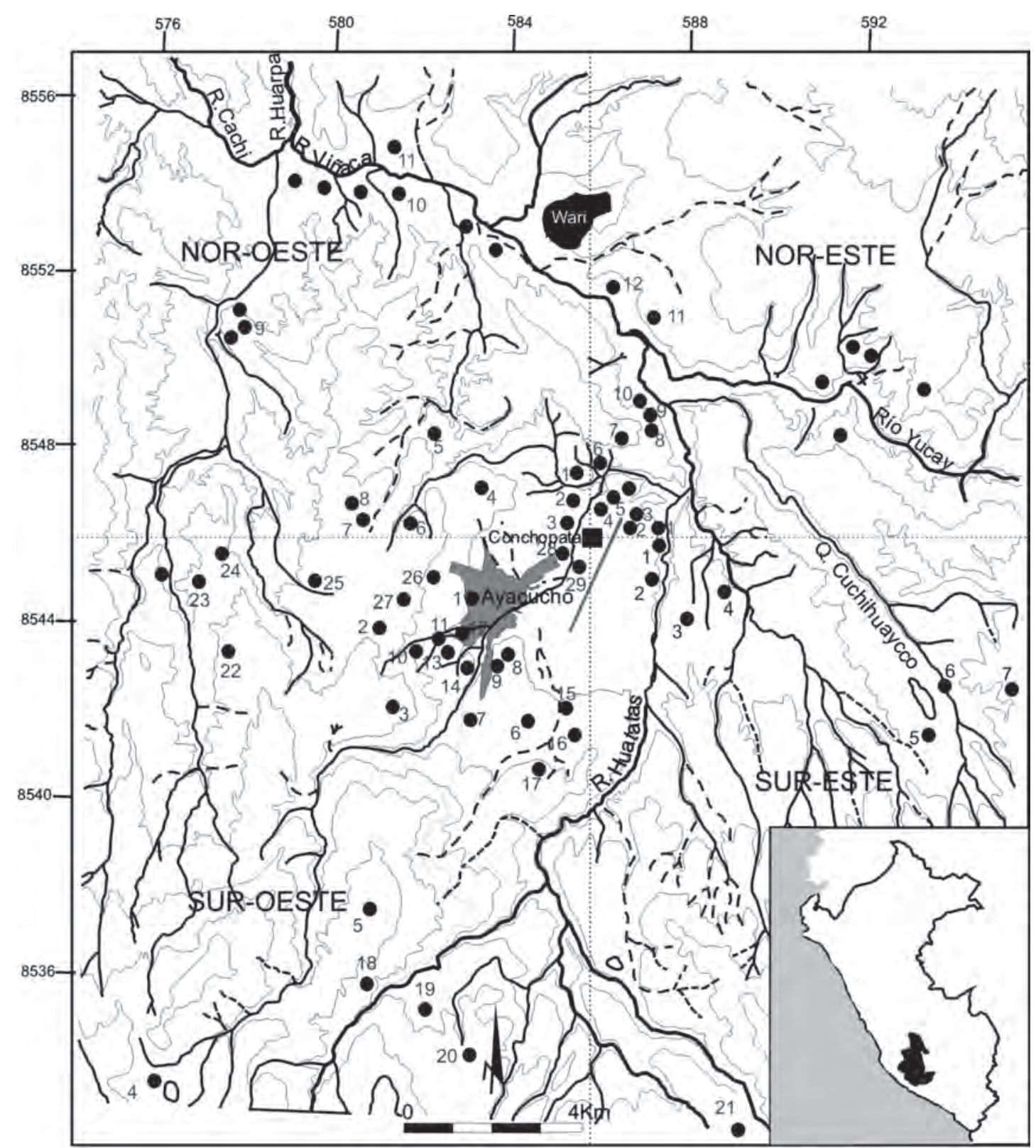

Figura 1. Distribución de sitios por zonas en la periferia del asentamiento de Conchopata. Zona noroeste: 1. Cueva Puente; 2. Tunasniyoc; 3. Totorilla; 4. Muyo Orqo; 5. Mollepata; 6. Pillpintuyoc; 7. Qoriwillca Chico; 8. Qoriwillca Grande; 9. Tanta Orqo; 10. Santiago de Paraiso; 11. Compañía. Zona noreste: 1. Yanamilla; 2. La Hoyada; 3. La Hoyada; 4. Gloriete; 5. Erapata; 6. Wichaqana; 7. Uma Orqo; 8. Viña Chiquita; 9. Sto Domingo; 10. San Miguel de Huamanga; 11. Yayapampa; 12. Huarancayoc. Zona sureste: 1. Chichupucro; 2. Viscachayoc; 3. Ichaypampa; 4. Santa Bárbara; 5. Condoray; 6. Cuchihuayqo; 7. Tambillo. Zona suroeste: 1. Aqo Wayqo; 2. Huascahura; 3. Cabrapata; 4. Condoray; 5. Campanayoc; 6. Yanama; 7. Quicapata; 8. Scuchimay; 9. Rudaqasa; 10. Iraqata; 11. Pilacucho; 12. La Unión; 13. Santa Ana; 14. Waychaupampa; 15. Tinajeras; 16. Nawimpuquio; 17. Ranrarranrra; 18. Lambrashuayqo; 19. Chupas; 20. Cueva Chupas; 21. Ayamachay; 22. Puka Orqo; 23. Qachisqo; 24. Auquimarca; 25. Pijoy; 26. Picota; 27. Kumunsenqa; 28. Totorilla. 


\section{ASENTAMIENTOS DE LA PERIFERIA NOROESTE}

Tiene como centro a las quebradas de Mollepata, Chillico y margen izquierda de los ríos Pongora, la Compañía y Viñaca, donde resaltan los núcleos poblacionales de la cueva Puente, Santo Domingo el Paraíso y Tanta Orqo a los que se anexan otros asentamientos menores.

Cueva Puente. Sitio Precerámico, localizado a un kilómetro en línea recta de Conchopata, a unos $200 \mathrm{~m}$ aguas arriba de los puentes que unen a Tunasniyoc y Wichqana (2700 msnm), Fue identificada y excavada por el equipo dirigido por Mac Neish entre 1969 y 1971 quienes reportan una secuencia cultural que comprende de 9000 a 1750 a.C. (Fig. 2), donde la fase Puente (9000-7000 a.C.), caracterizada por presentar una variedad de herramientas trabajadas en huesos como los buriles, agujas y cuentas tubulares que continúan hasta la fase Jaywa (7000-5800 a.C.). Uno de los rasgos de Puente es la gran cantidad de tipos de artefactos relacionados con actividades para la obtención de fuego con piedra pedernal y con punzones de asta, uso de martillos de piedra, yunques, varios tipos de núcleos parecidos a raspadores y bifaces; trabajo en pieles y de madera representados por grandes y pequeños cuchillos, y raspadores de lados retocados a los que se incluye artefactos para despellejamiento de animales cazados. Esta fase ocurrió en un periodo cuando los efectos del final del Pleistoceno probablemente se sintieron con mayor efecto en el medio ambiente, donde una biomasa disminuida pudo haber sido la condición que últimamente cambio esta fase cultural o siste-

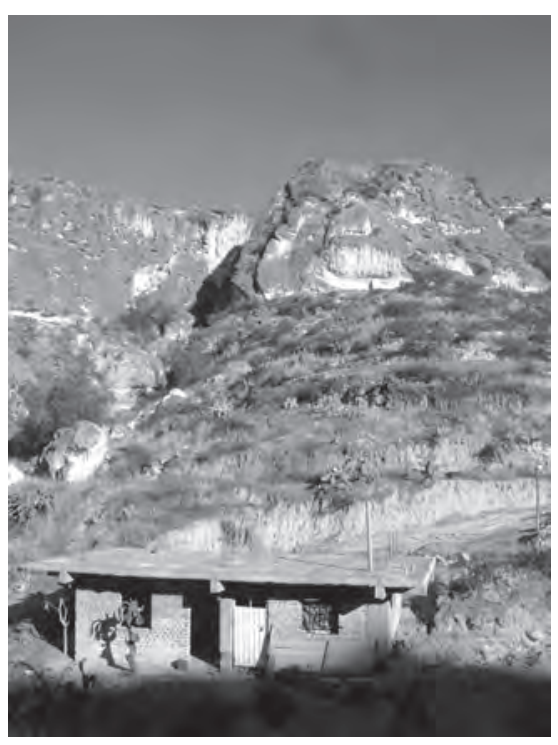

Figura 2. Cueva Puente amenazada por la construcción de viviendas modernas. ma en el nuevo Jaywa.

Tunasniyoc. Montículo cortado por la carretera Ayacucho-San Francisco, margen derecha de la quebrada Mollepata cerca de la confluencia con el río Totorilla, fue excavado por Lumbreras $(1974,1981)$, quien da cuenta de una población Huarpa reocupada en el periodo Wari y con antecedentes que vienen desde el periodo Formativo con un tipo de cerámica tricolor que identifica al estilo Tunasniyoc (Fig. 3).

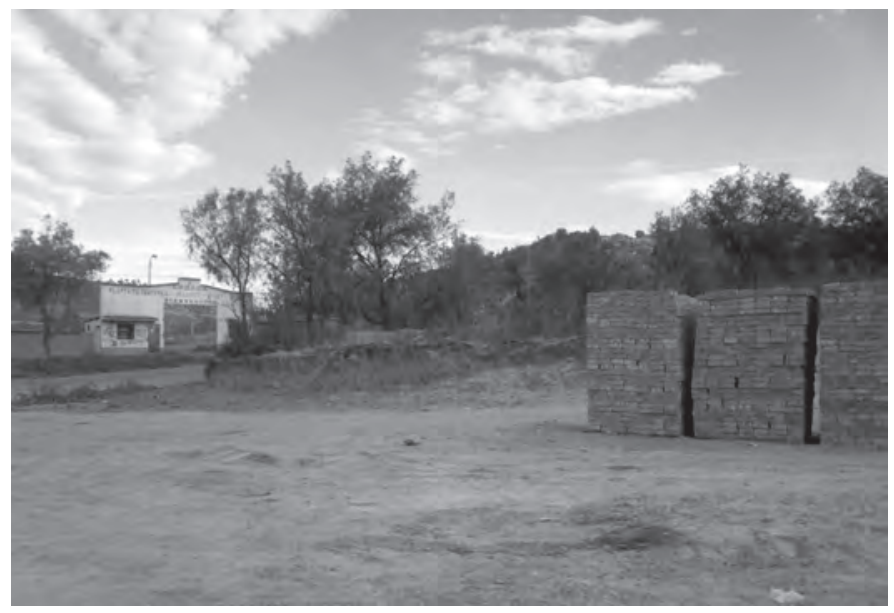

Figura 3. Destrucción irreparable de Tuunasniyoc y detalle del perfil norte con tumba Huarpa en forma de bota, arrasada con tractor en mayo de 2012.

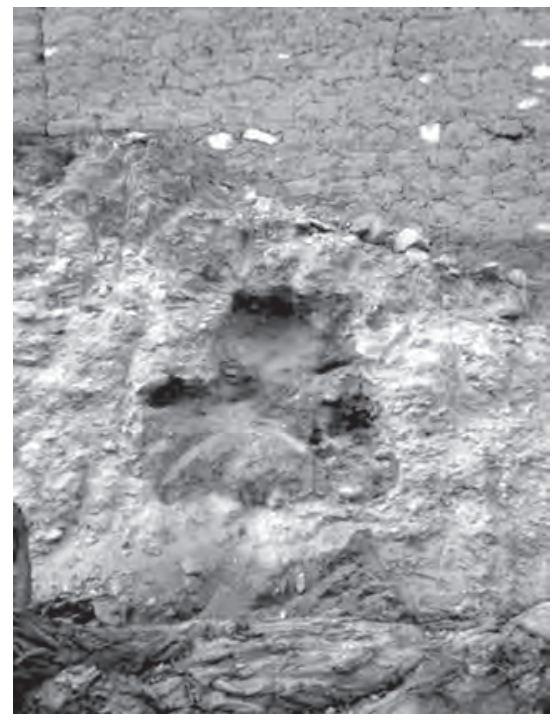


Totorilla A. Planicie que ocupa las lagunas de oxidación de la ciudad de Ayacucho, en cuyo lado que da al cauce del río existen restos de estructuras arqueológicas en formas de recintos cuadrangulares y rectangulares de canto rodado sepultadas por gruesas capas de material aluvial, y asociadas con cerámica Huarpa y Wari y así como una gran cantidad de azadas y azadones íntegros y fragmentados. Las estructuras se extienden hasta la quebrada Mollepata y es posible que hayan formado una misma unidad arqueológica con Tunasniyoc (Fig. 4).

Muyo Orqo. Colina de moderada elevación en el extremo noroeste del campo de la Universidad Nacional de San Cristóbal de Huamanga, parte alta del asentamiento «madre Covadonga». El sitio fue excavado

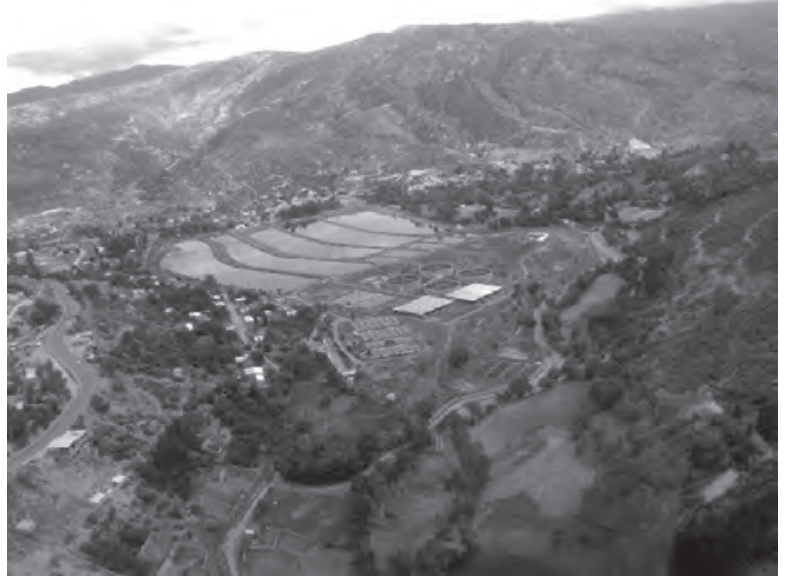

Figura 4. Área con restos de estructuras sepultadas con material aluvial sobre lo cual se ha construido las lagunas y pozos de oxidación. en varias oportunidades por arqueólogos de la UNSCH y del INC, quines develaron cerca de medio centenar de recintos cuadrangulares y rectangulares dispuestos en torno a patios centrales en los que destacan la forma arquitectónica de un reciento en «D» con patio delantero y recintos menores que funcionaron como viviendas talleres de producción de cerámica, con entierros humanos en tumbas circulares de la época Wari, que hacen pensar en un asentamiento urbano formalmente semejante pero de menor magnitud que Conchopata. El sitio está rodeado de canteras de arcilla y arenas con amplios terreno para el cultivo, en cuya superficie hay cerámica del periodo Formativo como antecedente de la ocupación Wari y Huarpa que ocupó la colina.

Mollepata. Asentamiento prehispánico con abundante cerámica los diferentes estilos Wari, pero también de la época Huarpa, dispersos en una extensa pampa o planicie que se inicia en las laderas occidentales del cerro Umaorqo y continua hasta las faldas de los cerros que delimitan con Qorihuillca, espacio está ocupado por el actual asentamiento de Mollepata en la margen izquierda de la quebrada de nombre homónimo. La extensión del sitio es de aproximadamente 10 ha. Tiene como centro el área por donde pasa un camino antiguo que viene por el lado norte y e proyecta hacia el sur cruzando la quebrada Mollepata.

Pillpintuyoc. Asentamiento establecido en la cima del cerro Pillpintuyoc al noreste de Qoriwillcca Chico, el sitio presente abundante cerámica Huarpa y Wari, al igual que artefactos líticos en la superficie de la cima y laderas del lado sur (Fig. 5). Es un lugar estratégico para la comunicación y contacto con otros poblados aledaños, tiene visión panorámica a los sitios de Mollepata, Muyo Orqo, Conchopata y Uma Orqo.

Figura 5. Quebrada Mollepata que separa a los cerros Picota y Pillpintuyoc en cuya cima hay fragmentos de cerámica de estilos Rancha, Huarpa y Huari.

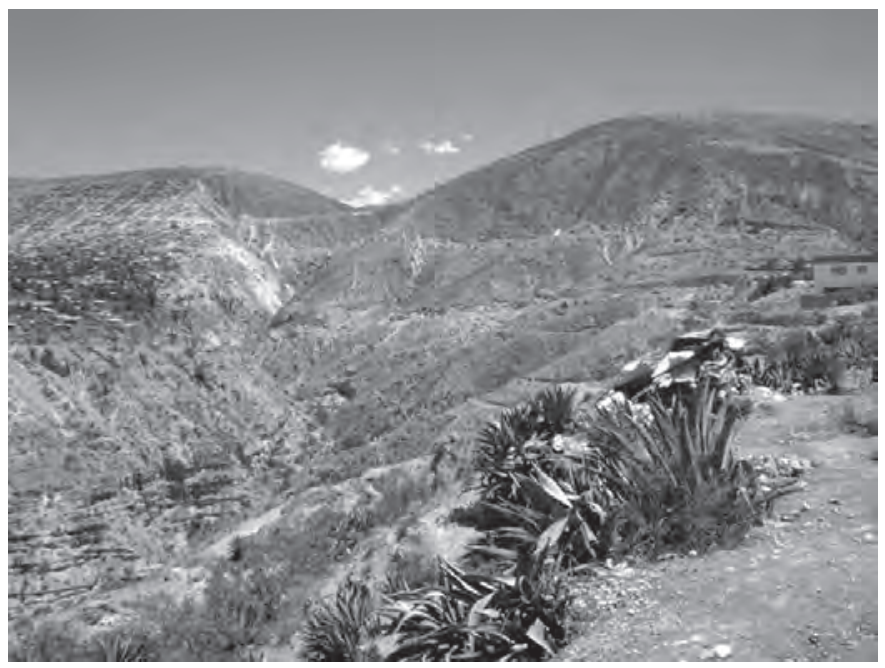


Qorihuillca Chico. Restos de distintos asentamientos dispuestos en lomas, promontorios y colinas que rodean al centro poblado de Qorihuillcca Chico, el cual a semejanza del anterior tiene como centro el lecho de una antigua qocha, donde a la vez hay vestigios de caminos, terrazas y estructuras menores asociados con cerámica de los periodos Formativo, Huarpa, Wari y Chanka. En la zona destaca el sitio excavado por Alarcón (1999).

Qoriwillcca Grande. Conjunto arqueológico constituido de varios promontorios y colinas dispuestos uno a continuación de otros y enlazados con una interesante red de caminos, terrazas y qochas prehispánicas cuyos restos son perceptibles en la superficie del suelo arcilloso y árido que predomina en el lugar como parte de la configuración geográfica de la microcuenca del río Viñaca. En nuestro recorrido hemos encontrado abundantes artefactos líticos y cerámica de filiación formativa, Huarpa, Wari y Chanka. El área cultural del sitio sobrepasa las $10 \mathrm{Ha}$, convirtiéndola una de las zonas de mayor intensidad poblacional durante la época prehispánica.

Tanta Orqo. Centro poblado establecido en la cima de una colina con derrumbe geológico en el lado oriental donde se encuentra el actual pueblo de Trigopampa, margen derecha del curso inferior del río Chillico. Presenta estructuras circulares con abundante cerámica Huarpa, pero también hay fragmentos de filiación formativa, Wari y Chanka. Es uno de los asentamientos de mayor magnitud después de Ñawimpuquio y está rodeado de otros asentamientos como Huancaqasa, San Francisco, Chillcaccasa y Tunasmoqo. Fue registrado por Benavides (1976), Pérez (1999) y Doig (2002).

Santiago de Paraíso. Restos de arquitectura planificada en el área que ocupa el actual centro poblado Santiago de Paraíso margen izquierda del río La Compañía. En las partes alteradas por la construcción de viviendas se observan secciones de un muro perimétrico al que se adosan otros muros menores que forman diferentes espacios cuadrangulares y rectangulares (Fig. 6). En la superficie del terreno que rodea al poblado hay cerámica de los periodos Formativo, Huarpa y Huari.

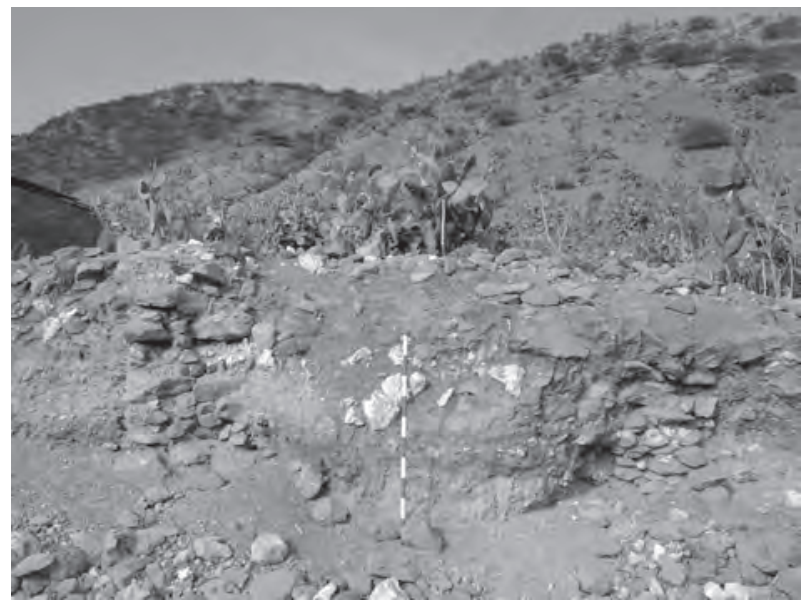

La Compañía. Centro poblado de las épocas Huarpa y Huari sepultado por gruesas capas de material aluvial traído por la quebradas del mismo nombre, cuyas evidencias se encuentran dispersas desde el área donde se ubica el actual cementerio hasta la altura de la carretera que pasa por la margen derecha de dicho valle (Fig. 7). Los restos que se observan en los perfiles y espacios utilizados como canteras de arcilla para elaboración de adobes, indican que se trata de un extenso

Figura 7. Paramento de estructura Wari sepultada por alud de arcilla arrastrada por una intensa precipitación fluvial en la quebrada Compañía.

Figura 6. Secciones de muros destruidos por la construcción de viviendas actuales, noviembre 2010.

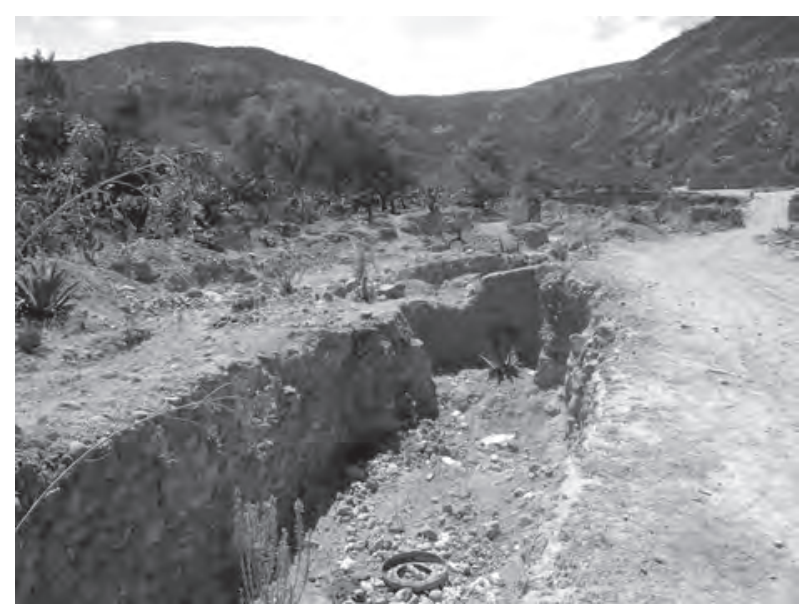


poblado dividido en sectores con sus respectivas áreas de circulación, viviendas, áreas de producción artesanal y drenajes propios de una planificación urbana.

\section{AsentAMientos DE LA PERIFERIA NORESTE}

Comprende al espacio geográfico determinado por la confluencia de los ríos Huatatas y Totorilla que forman el Santo Domingo conocido aguas abajo como río Chacco, donde destacan los núcleos poblacionales de Uma Orqo, Glorieta, Santo Domingo, Ayacucho, Yayapampa y Chacco.

Yanamilla. Canteras de arcilla, restos de canal y camino que bordea el lado noreste y sureste de la planicie donde se ha construido el penal de Yanamilla. Las canteras son de arcilla para la elaboración de vasijas y quicato como los que aparece utilizado en pisos y morteros de Conchopata y otros sitios Wari; el canal según su proyección nace del reservorio de Canaan donde debió de existir una qocha, acondicionada para recibir agua canalizada desde Lambrashuayqo. Los restos del camino se proyectan cruzando el río Huatatas.

La Hoyada. Camino prehispánico localizado a menos de un kilómetro de Conchopata en el lugar denominado la Hoyada adyacente, al penal de Yanamilla, se caracteriza por llevar gradas y estar delimitado en ambos lados con piedras paradas, mide 1,50 $\mathrm{m}$ de ancho y está hecho a base de piedras de río, algunas piedras grandes forman los pasos y contrapasos de un tramo en zigzag de $50 \mathrm{~m}$ de largo, este camino se proyecta en dirección a Santa Bárbara, Condoray y Tambillo y desde allí al valle del río Pampas (Fig. 8), fue cortado por la construcción del viejo y actual aeropuerto.

La Hoyada. Cerámica del periodo Formativo y Huarpa dispersa en la ladera superior norte que bordea las actuales instalaciones del cuartel Los Cabitos (sitio Chaquipampa según Menzel 1968), el sitio esta cortado por la carretera Ayacucho-Yanamilla. La Hoyada es un espacio hundido dispuesto en forma de «U» con el lado abierto orientado hacia el noreste, formado por una entrante que delimita la planicie del actual aeropuerto y actual asentamiento de Yanamilla (Fig. 9), el fondo aparece rodeada de terrazas y aparentes estructuras habitacionales de las épocas Huarpa y Wari dispuestas en por lo menos tres niveles del fondo de una antigua depresión o qocha.

Gloriete. Cerro ubicado en la margen derecha de la quebrada Totorilla a menos de un kilómetro de Conchopata, el sitio establecido en la cima (Fig. 8), presenta alineamientos de recintos hechos con piedra de río de un asentamiento aldeano, cercano al templo ceremonial de Wichqana asociado con cerámica perteneciente a los periodos Formativo, Huarpa, Wari y Chanca.

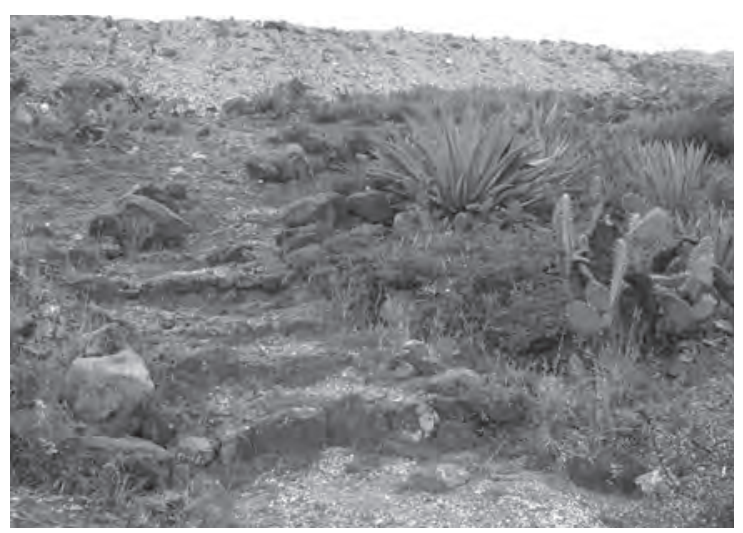

Figura 8. Restos de camino con gradería en La Hoyada.

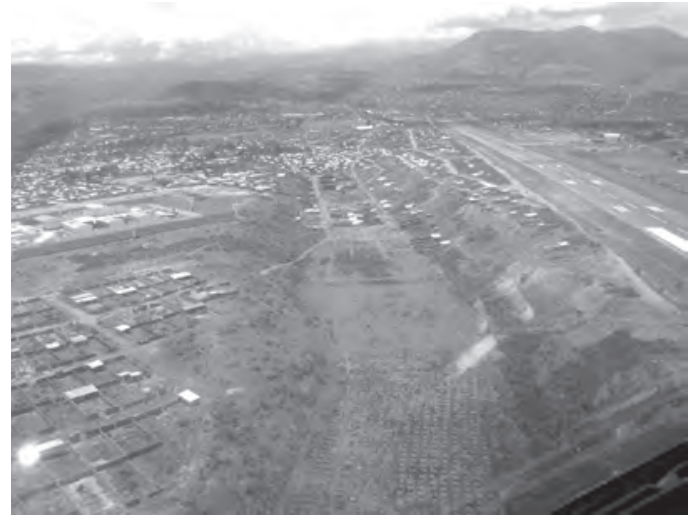

Figura 9. La Hoyada entre Yanamilla y la pista del actual aeropuerto. 
Erapata. Contiguo y separado de Gloriete por una angosta pero profunda quebrada formada por erosión fluvial (Fig. 10). El asentamiento presenta cabeceras de estructuras con abundantes fragmentos de cerámica, los cuales se extienden desde la cima hasta la ladera noreste del promontorio rocoso de lava volcánica, la cerámica asociada a la superficie pertenece a los periodos Formativo, Huarpa y Wari, incluye tiestos de asas de doble cordón y fragmentos de enlucidos con improntas de pared de quincha semejante a las encontradas en las excavaciones de Raúl Mancilla Mantilla en Ira Qata o Pilacucho.

Wichqana. Perfiles estratigráficos y superficie de terreno con abundante material cul-

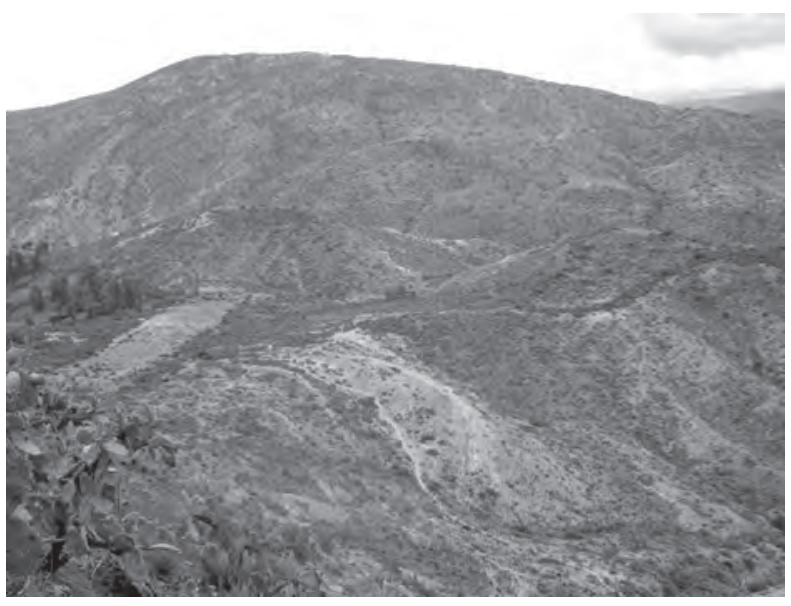

Figura 10. Ubicación de Gloriete, Erapata y Uma Orqo. tural del periodo Formativo asociado al área

del templo ceremonial dispuesto en forma de «U», definido a inicios de la década del 70 por Luis Lumbreras, con a referencias previas de Gary Vescelius, Isabel Flores, José Casafranca y John Rowe. El sitio atraviesa por un delicado estado de conservación destinado a desaparecer por las instalaciones de dos gasolineras que estan promoviendo la construcción de nuevas viviendas dentro de la zona arqueológica (Fig. 11).

Uma Orqo. Asentamiento poblacional disperso en varios promontorios o salientes de la cima del cerro Uma Orqo, al noreste de Mollepata en el distrito de Nazarenas (Figs. 10 y 12). El cerro presenta profundas laderas erosionadas en los lados norte y sur mientras que los lados oeste y este están conectados a restos de un camino que desciende hasta la confluencia de las quebradas Totorilla con Huatatas por donde se accede a Conchopata. Presenta alineamientos de canto rodado como parte de terrazas, caminos y estructuras habitacionales asociadas con cerámica de los periodos Formativo, Huarpa, Wari y Chanka, a parte de una variedad de instrumentos y desechos líticos como hachas, porras y piedras con hoyuelos como los que se utilizan en el proceso de la metalurgia.

Viña Chiquita. Pintura rupestre y petroglifos dispuestos en la quebrada Viña Chiquita en lado oriental de Uma Orqo (Figs. 13, 13a y 13b), Lo primero consiste en borrosas imágenes de camélidos pintados de color Rojo y los segundo corresponde a la modalidad de pocitos tallados en diferentes rocas de lava volcánica que afloran en la ladera cortada por la carretera Ayacucho-Huanta (km. 7).

Santo Domingo. Secciones de tumbas circulares y estructuras habitaciones dispuestas en la parte superior de un montículo cortado por la carretera, altura del puente Muyurina, además en el escombro depositado al pie de

Figura 11. Restos de Wichaqana afectados por la ampliación de una gasolinera, setiembre 2010.

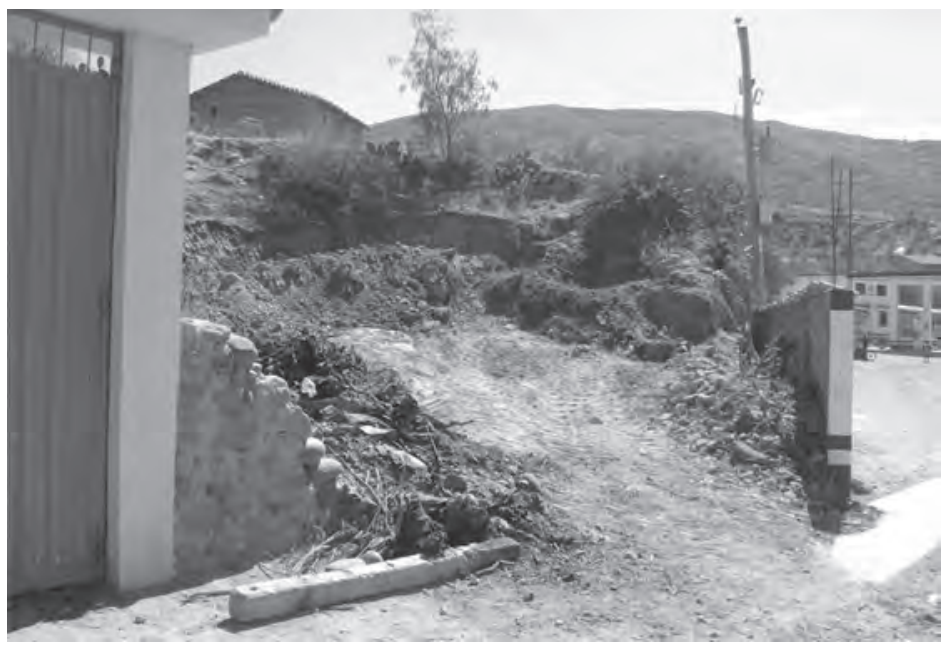




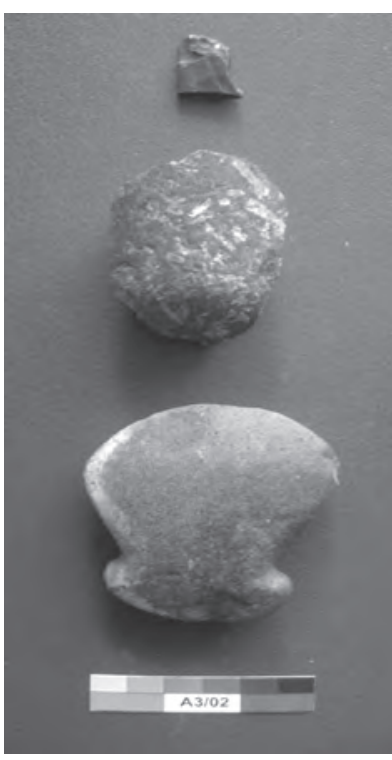

Figura 12. Artefactos líticos del cerro Uma Orqo.

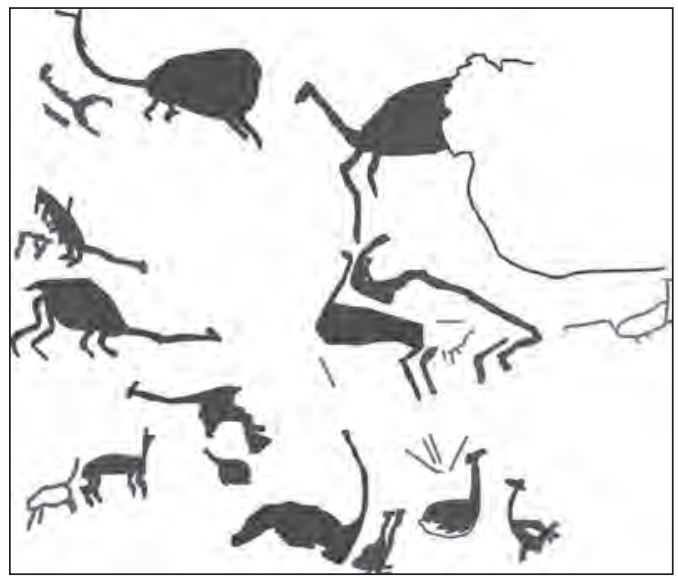

Figura 13a. Conjunto de camélidos.

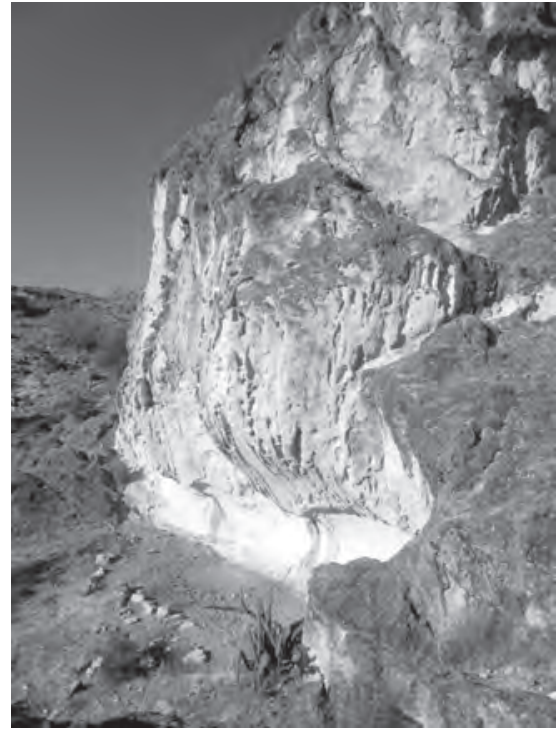

Figura 13. Abrigo de Cuchimachay con restos de pintura rupestre.

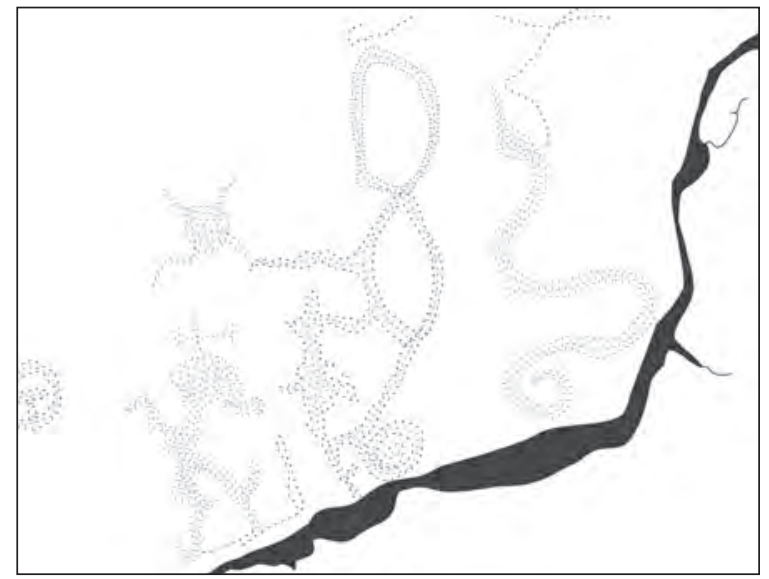

Figura 13b. Petroglifos sobre pintura rupestre.

la carretera hay abundantes fragmentos de cerámica principalmente de la época Wari (Fig. 14), por lo que puede tratarse de un asentamiento de carácter administrativo para controlar la economía de la zona. Este sitio aparece mencionado por Lumbreras (1974).

San Miguel de Ayacucho. Secciones de estructuras y rellenos arquitectónicos asociados con restos óseos y cerámica Wari en el perfil de la carretera Ayacucho San Francisco (Km. 11), el sitio fue excavado en la década del 90 por Regina Tapahuasco y Marlene Cárdenas Riveros, quienes informan de la presencia de recintos habitacionales con tumbas de forma cilíndrica (Fig. 15). De la capa estéril de este sitio procede parte del fémur de de un animal pleistocénico como los restos encontrados en la cueva de Pikimachay.

Maizondo. Estructura ceremonial y funeraria en la parte superior de los cerros con barrancos empinadas que descienden a formar el lado derecho del valle de Chacco. El primero es un recinto en «D» 


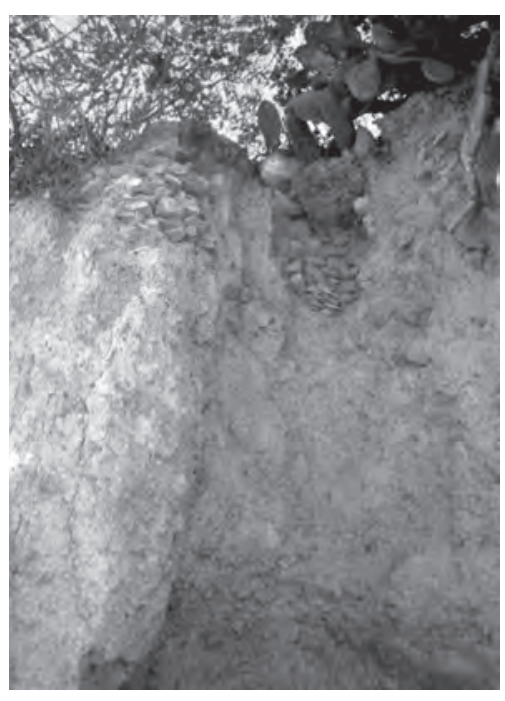

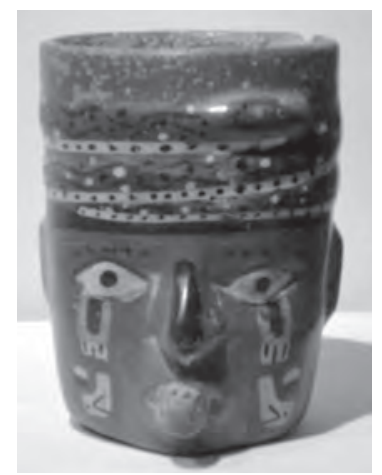

Figura 14. Secciones de tumbas de forma cilíndrica en la parte superior de perfil cortado por la carretera AyacuchoQuinua, altura de Muyurina y vasija procedente de tumbas adfyacentes (colección Museo regional de Ayacucho).

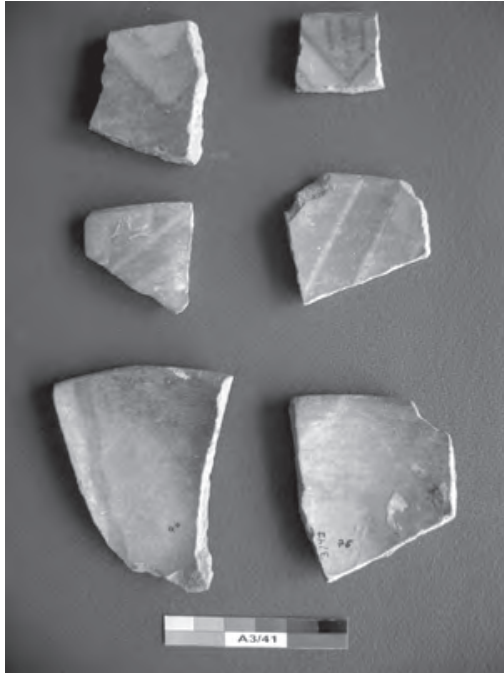

Figura 15. Cerámica Wari procedente de la zona de San Miguel de Huamanga.

con el lado recto orientado al norte, tiene $8,80 \mathrm{~m}$ de diámetro $70 \mathrm{~cm}$ de ancho de los muros hechos con bloques de lava volcánica, cuya cabecera está casi a ras del piso; el segundo es una cámara acondicionada a la saliente de una cavidad arcillosa y rocosa, la cual si bien esta disturbada conserva su altura original con acceso orientado hacia el oeste, el interior es utilizado como espacio sagrado para depositar ofrendas o pagos por los pobladores del lugar.

Huarancayoc. Muros de contención de plataformas asociadas a montículos con cerámica del periodo Formativo Inferior en la parte superior de los cerros que rodean el actual cementerio de Chacco (Figs. 16, 16a y 16b) próximo a la confluencia de la quebrada Checclla Huayco al río Pongora.

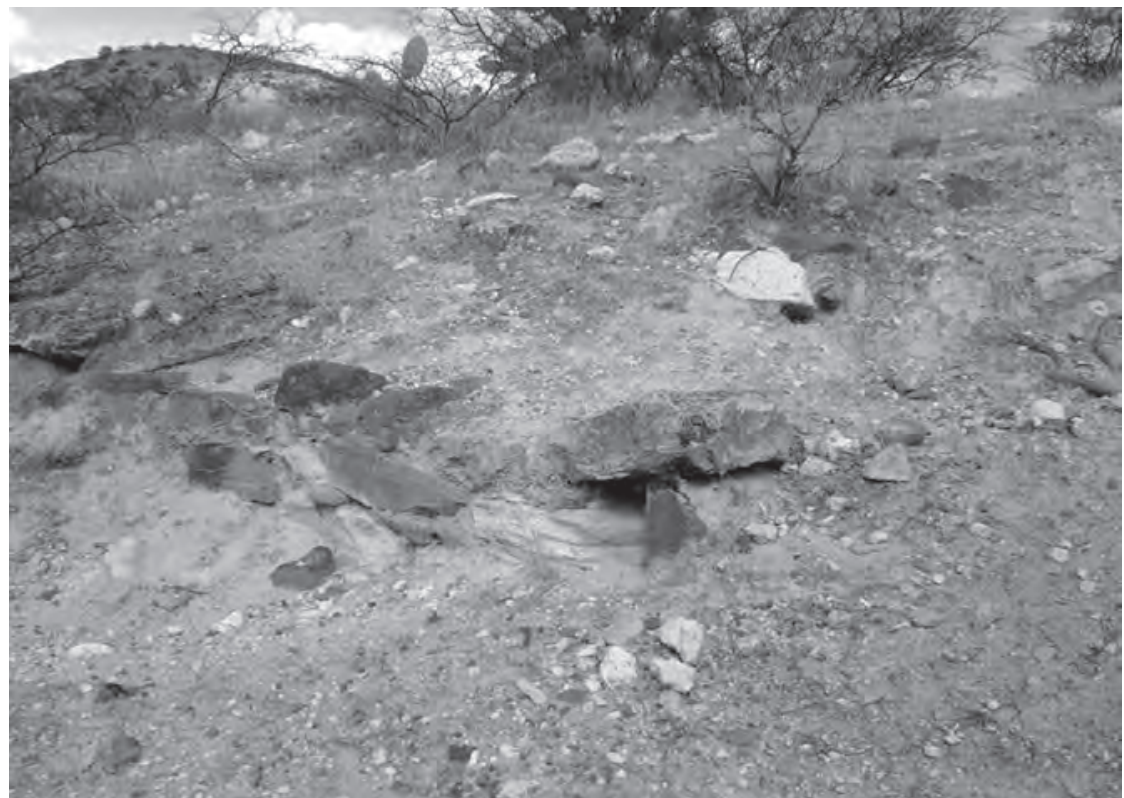

Figura 16. Restos de plataforma en Huarancayoc. 

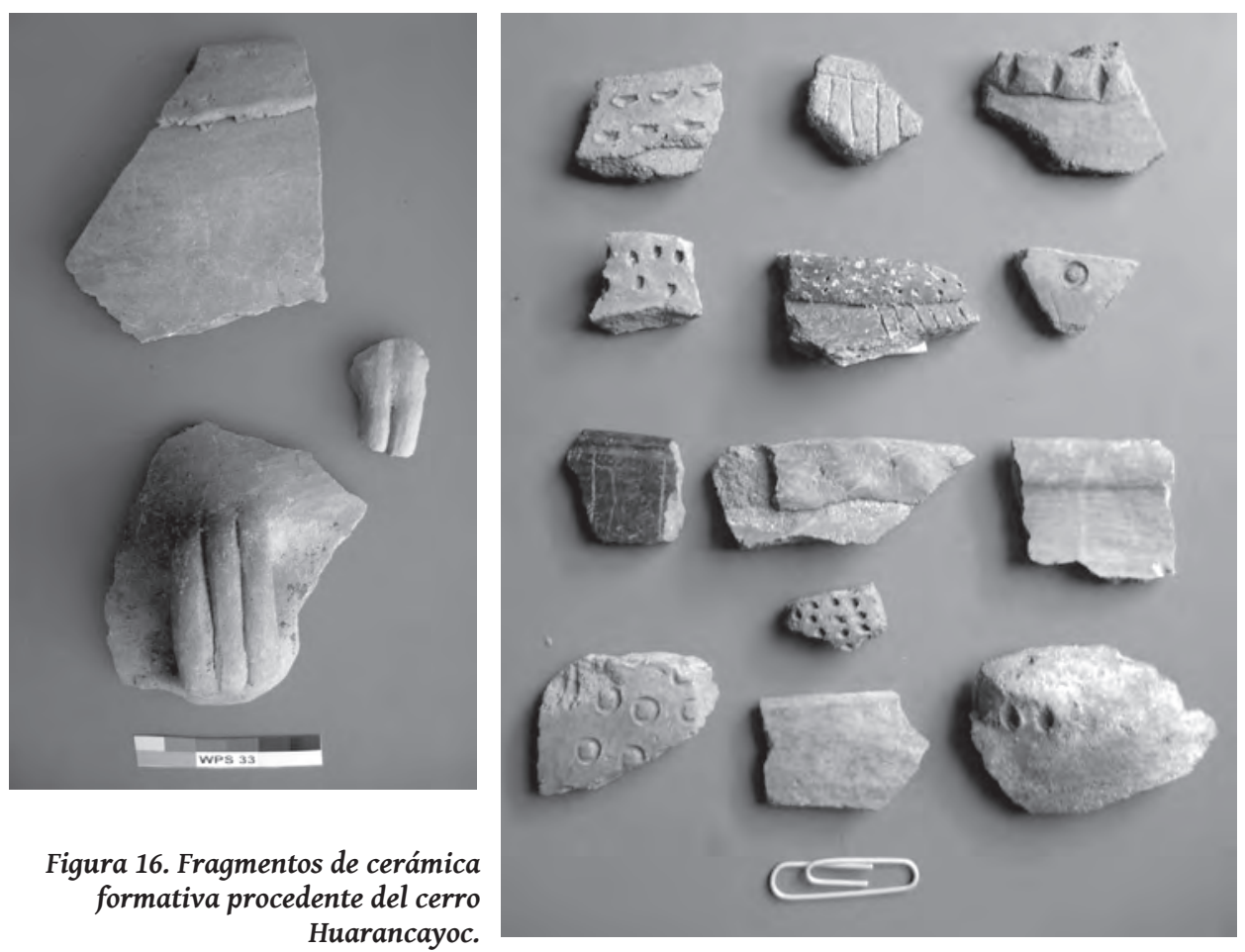

Figura 16. Fragmentos de cerámica formativa procedente del cerro Huarancayoc.

\section{ASENTAMIENTOS DE LA PERIFERIA SURESTE}

Comprende los valles de Santa Barbara, Niño Jesús de Ñeque, Condoray y Tambillo por conectados a restos de caminos que se proyectan a Conchopata. En esta zona destacan los asentamientos localizados en la Hoyada, Santa Barbara y las quebradas Cuchihuayqo y Yucaes.

Ichuypampa. Establecimiento ubicado en la margen derecha de la quebrada Coneja a $2 \mathrm{~km}$ en línea recta de Conchopata, por donde pasa un camino antiguo que se proyecta uniendo a diferentes asentamientos en dirección a Chiara. Consiste en los restos de un poblado establecido en la parte superior donde hay laderas y dos largos promontorios que forman una extensa qocha, quizá la de mayor magnitud en la periferia de Conchopata (Fig. 17). En la superficie del terreno hay restos de estructuras habitacionales y funerarias así como cerámica de los periodos Formativo, Huarpa y Wari.

Chichupucro. Asentamientos aldeanos establecidos en dos promontorios en las laderas que descienden del lado sureste de planicie de Yanamilla, margen izquierda de la quebrada Huatatas y al pie de la carretera que sale al grifo Paluco, los asentamientos presentan restos muros de contención y recintos habitacionales asociados con cerámica de los periodos Formativo, Huarpa y Wari (Figs. 18 y 18a). Los sitios están separados uno del otro a menos de un kilómetro de distancia, ambos asociados hacia el oeste con amplios espacios agrícolas en terrenos planos y semihundidos que parecen haber sido antiguas qochas.

Viscachayoc. Cerámica de las épocas Huarpa y Wari, dispersas en el borde del acantilado conocido como Vizcachayoc, margen izquierda de la quebrada del mismo nombre, donde existe abundante cerámica de las épocas Huarpa y Wari: Las profundidad del acantilado es una zona pedregosa donde abunda las vizcachas de donde proviene el nombre del lugar.

Santa Bárbara. Complejo arqueológico ocupa la parte alta de Santa Barbara a $5 \mathrm{~km}$ de Conchopata. Corresponde a uno de los asentamientos de mayor magnitud con restos de terrazas agrícolas y habita- 


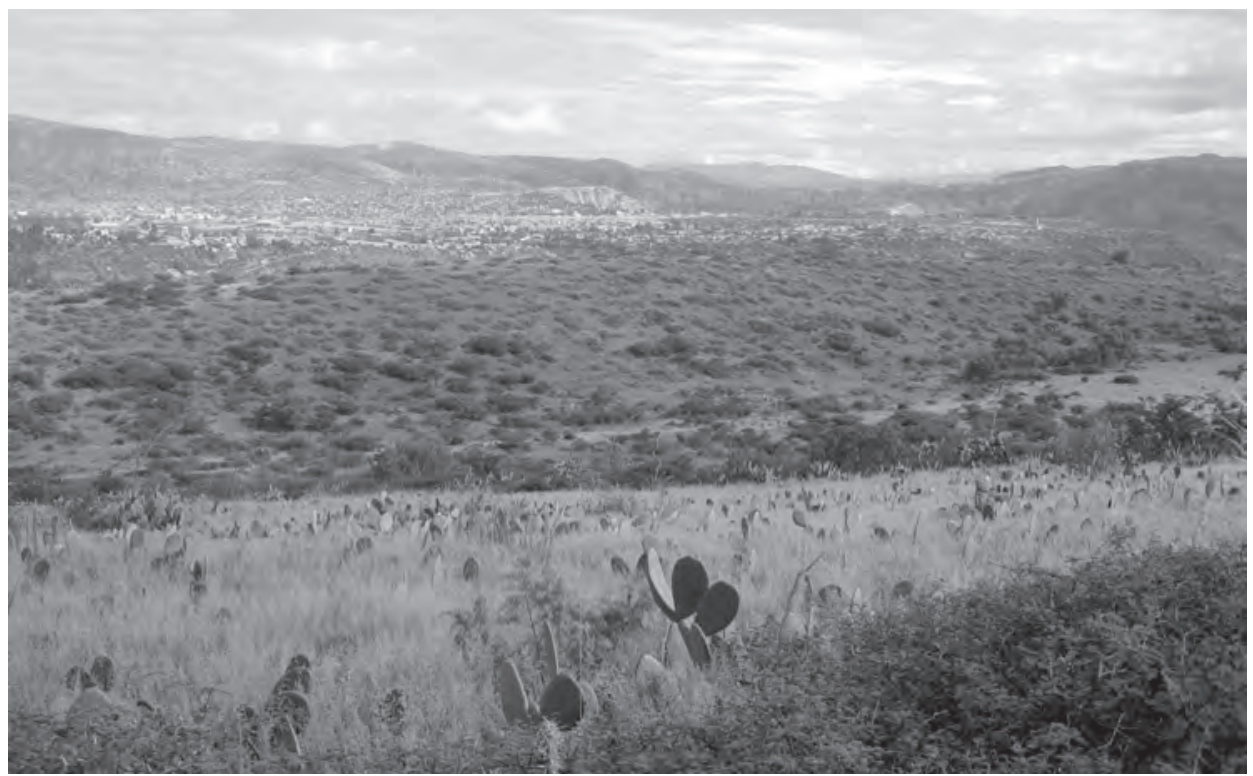

Figura 17. Planicie con restos culturales de Ichuypampa.

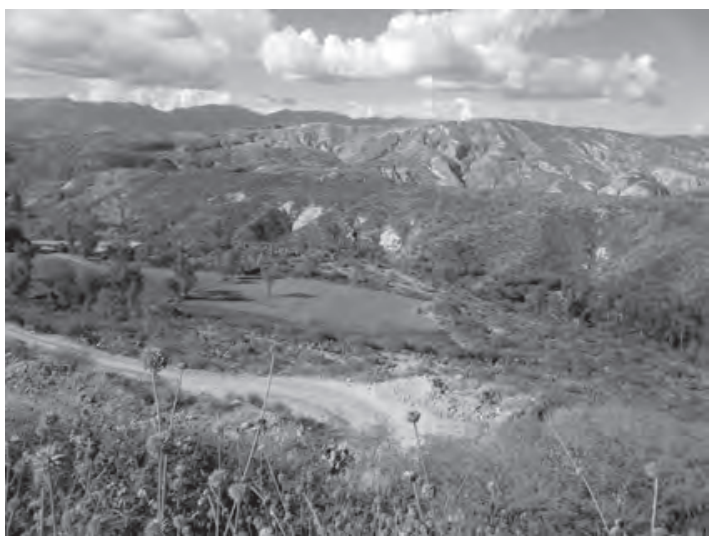

Figura 18. Chichupucro, montículo norte.

cionales, caminos, cuevas, estructuras y cerámica dispersa en una extensa área sobre la carretera que va al Cusco y cortado por el camino carrozable que va al poblado de Rayminas.

Condoray. Asentamiento disperso en la cima y planicie del cerro Condoray, por donde pasa restos de un camino antiguo que viene de Wari y va hacia el sur en dirección a Acocro (Fig. 19), en la superficie del lugar abundan fragmentos artefactos líticos y cerámica de filiación Formativa, Huarpa y Wari.

Figura 19. Colina de Condoray con restos de asentamiento asociado a camino.

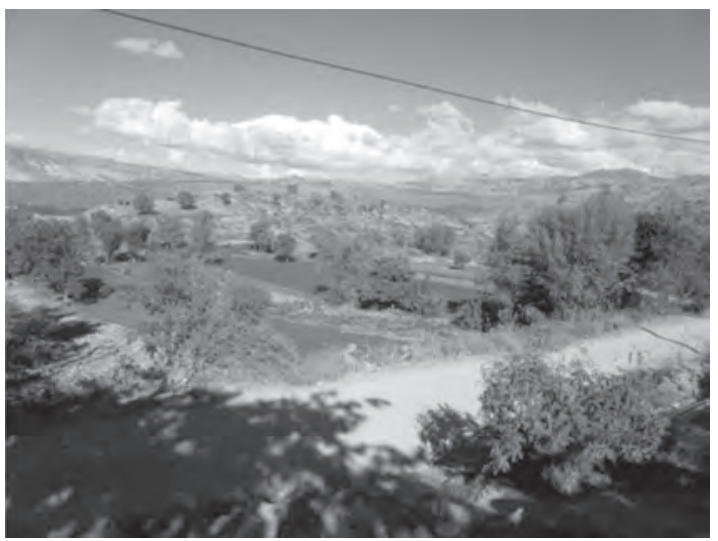

Figura 18a. Chichupucro, montículo sur.

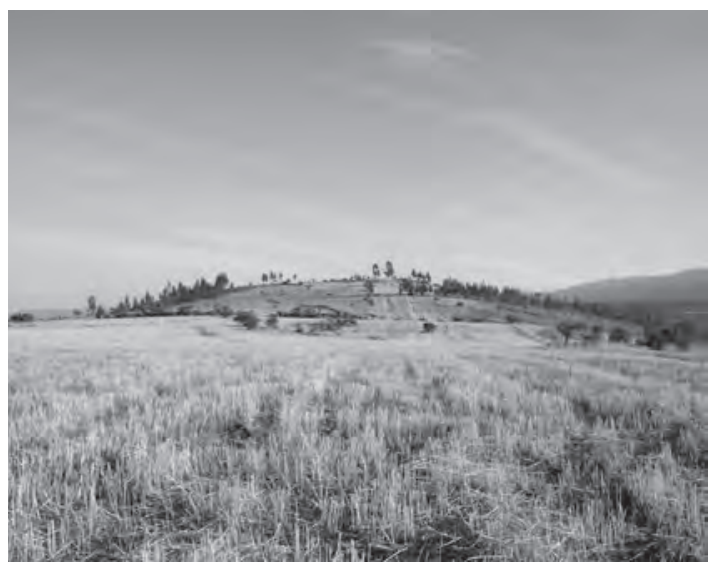




\section{Figura 20. Representación de una mujer} en balsa en los petroglifos de Cuchihuayqo.

Cuchihuayqo. Quebrada con petroglifos ubicada entre los poblados de Condoray y Tambillo por donde pasa un camino antiguo que viene de la selva y llega directamente a Conchopata. Los petroglifos están elaborados en las peñas de ambas márgenes de la quebrada en una distancia aproximada de $1 \mathrm{~km}$, los motivos corresponden a figuras de camélidos, cérvidos, felinos, perros, culebras, representaciones humanas, círculos concéntricos, espirales, aspas, líneas y puntuaciones que integran diferentes escenas hechos a base de incisiones y picados en las paredes verticales de las peñas que delimitan el actual cauce de la quebrada Cuchihuayqo (Fig. 20). Cerca del lugar hay asentamientos abiertos con cerámica de los periodos Formativo, Huarpa y Wari que sirve de referente para la determinar la filiación cultural de los petroglifos.

Tambillo. Superficie de terreno con abundante material lí-

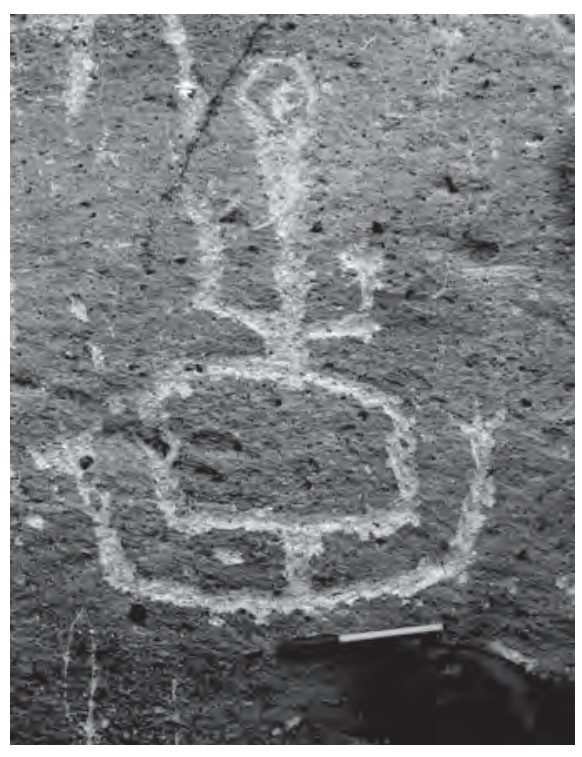
tico y cerámica Huarpa y Wari, en chacras y terreno del actual campo deportivo, donde al parecer queda los restos arquitectónicos de una población dispersa en el área que ocupa el actual pueblo de Tambillo.

\section{AsentAMIENTOS DE LA PERIFERIA SUROESTE}

Integrada por la zona de donde provenía el agua que abastecía a los antiguos pobladores de Conchopata, que tiene como centro la cuenca superior y media del río Huatatas donde se encuentran el complejo ceremonial de Chupas y Ñawimpuquio registrados por Mac Neish et al. 1981 y Lumbreras (1974, 1981), y otros monumentos.

Aya Orqo. Colina de aspecto troncocónica rodeada de terrazas y seccionada por la carretera Libertadores en la parte alta de Huascahura divisoria de las aguas que bajan a las microcuencas de los ríos Alameda y Chillido (Figs. 21 y 21a). El sito se caracteriza por presentar

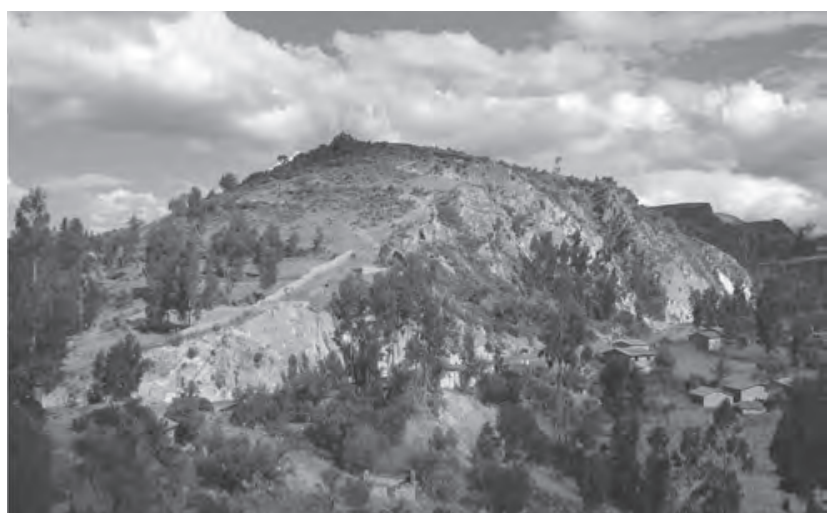

Figura 21 Colina del lado oriental de Aya Orqo.

Figura 21a. Cerámica del periodo Formativo estilo Chupas y Rancha procedente de Aya Orqo.

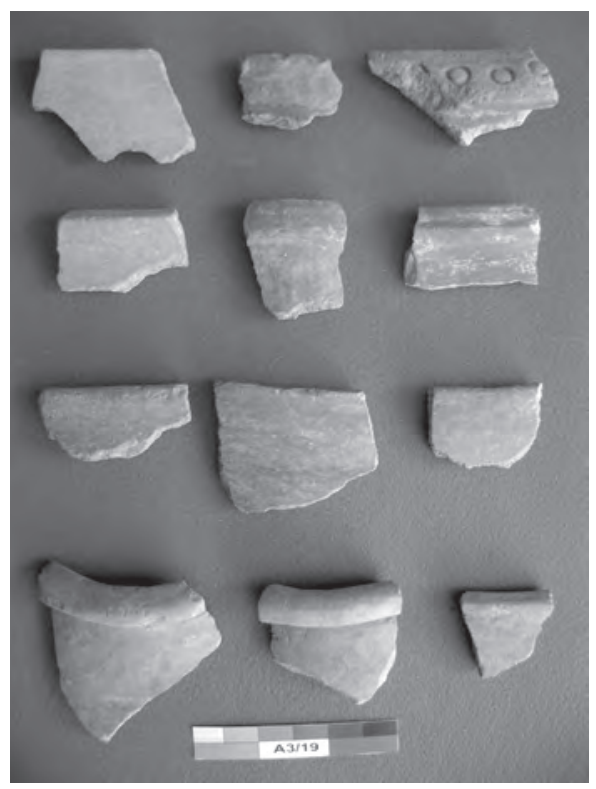


cerámica desde el formativo inferior hasta la transición Chanka Inca. Adyacente al sitio continua diferentes sitios (Cabrapata, La Cruz, Chocan, etc.) integrantes de un núcleo cultural que tiene como centro el poblado de Huascahura establecido en el fondo de una hondonada que parece corresponder a una antigua Qocha.

Chocan. Asentamiento poblacional disperso en la cima del cerro la Cruz que delimita el lado oeste del centro poblado de Huascahura, el sitio contiene abundante cerámica de los periodos Formativo, Huarpa, Wari y Chanka; artefactos y desechos líticos en medio de chacras delimitados con pircas hechas con piedras procedentes de las estructuras arqueológicas destruidas para la expansión agrícola, tal como se deduce de las cabeceras de algunos recintos circulares dispuestos en las inmediaciones del promontorio donde la población tiene instalado una cruz. Chocan es el nombre de un tipo de cerámica del periodo Formativo definido por Lumbreras (1974).

Cabrapata. Colina de mayor elevación que cerca el lado sureste de la ciudad de Ayacucho, margen izquierda del río Alameda, suelo formado de lava volcánica que contiene obsidiana en pequeñas bolas, y afloramientos de basaltos y andesitas. En la cima de Cabrapata hay una extensa qocha rodeada de promontorios con estructuras arqueológicas de recintos circulares, con abundante cerámica en medio de terrenos cultivados, hay espacios no alterados que contienen las bases de lo que podría corresponder a tumbas. El material cerámico predominante pertenece a las épocas Huarpa y Wari, pero también hay fragmentos de objetos con asas de doble cordón, bordes de ollas sin cuello propios del periodo Formativo, además de una variedad de artefactos y desechos de talla lítica en obsidiana, cuarzo, basalto, andesita, silex, etc.

Condoray. Cerro de mayor elevación en el lado sureste del pueblo de Socos, contiene diferentes estructuras como un conjunto de recintos circulares hechos de piedras paradas como base de viviendas tipo chozas de evidente filiación precerámica, luego siguiendo la planicie del lado sureste podemos percibir restos de un asentamiento con estructuras y cerámica de los periodos Formativo y Huarpa, un poco más al sur existe un conjunto de viviendas circulares con cerámica Chanka, y cerca una pequeña colina amurallada con restos de una población fortificada en diferentes niveles que rematan en una plataforma superior, parte de cual aparece disturbada con abundante huesos y cerámica Wari y Chanka, a lo que se debe agregar la presencia de diferentes entierros en pequeñas cuevas y acantilados.

Campanayoc. Centro poblado de las épocas Huarpa, Wari y Chanka, ubicado en la parte superior del cerro Campanayoc que domina el lado sur de ciudad de Ayacucho (Fig. 22). Corresponde sin duda al sitio de mayor altitud cuya población debió dedicarse a la agricultura de productos altoandinos, ganadería y pastoreo de camélidos sudamericanos. En el lado sur contiguo a la cima hay por lo menos tres colinas con restos de estructuras circulares, terrazas, graderías, recintos funerarios y caminos cercanos a fuente de agua, abundante cerámica y restos óseos en chacras y espacios cortados por la caminos y canal actual de irrigación así como el cementerio instalado en la misma cima del indicado cerro.

Yanama. Restos de terrazas de cultivo temporal ubicadas en la ladera de la zona conocida como Yanama al sur de Quicapata y al suroeste de Ñawimpuquio, por la cerámica dispersa en la superficie el correspondería al periodo Formativo Superior y Huarpa. En los últimos años la zona a sido objeto de invasión y sobre los restos arqueológicos se ha lotizado y construido nuevas viviendas.

Quicapata. Restos de horno con ceniza, escoria y fragmentos de cerámica Huarpa Tricolor, encontrados de manera circunstancial cuando se efectuaba la ampliación en las instalaciones del cuartel Quicapata. La información fue recogida por Ulises Larrea Morales en 1995.

Acuchimay. Fragmentos de cerámica Huarpa y Wari dispersa en la superficie de la cima del cerro Acuchimay, espacios disturbados y ocupados por viviendas modernas construidas sobre la boca o cráter de un viejo volcán. 


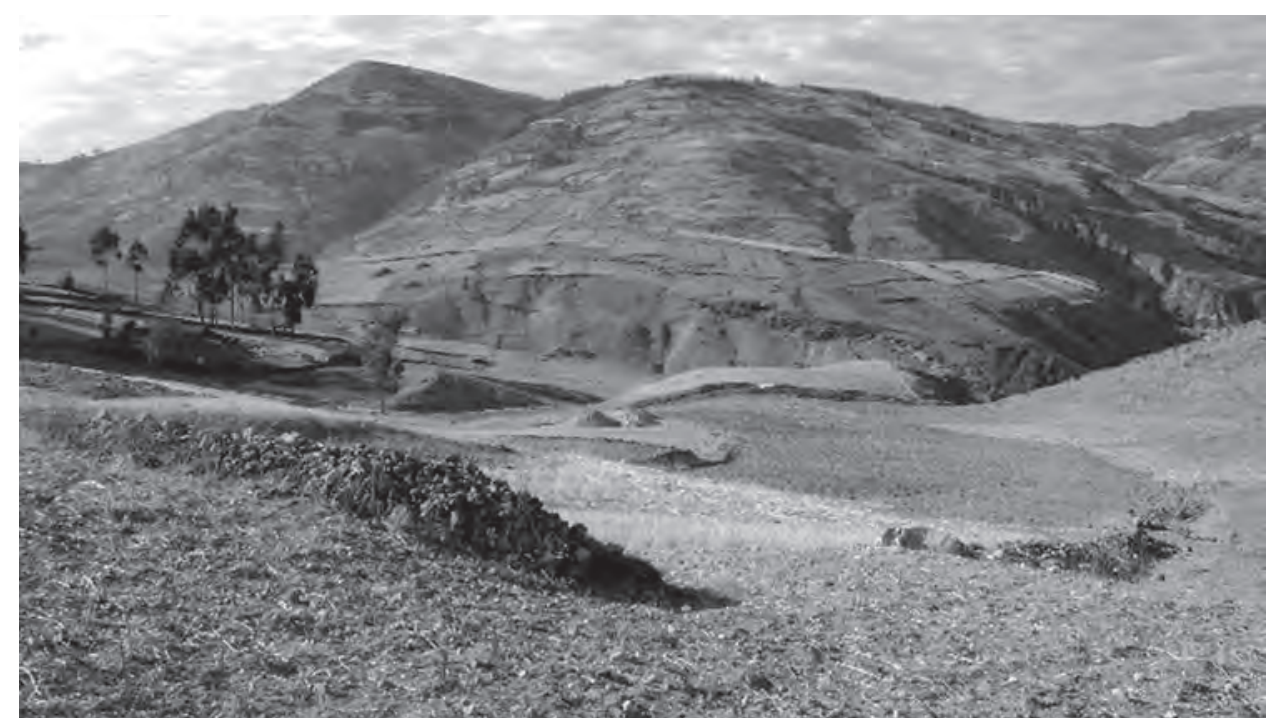

Figura 22. Vista de Campanayoc ( ${ }^{-}$lado izquierdo) desde Cabrapata. Obsérvese los alineamientos de un complejo sistema de andenerías preincaicas construidas desde el Formativo Superior

Rudaqasa. Restos de viviendas circulares de las épocas Huarpa y Wari localizadas en el sector de Rudaqasa en el lado suroeste de la cima del cerro Acuchimay. Los restos arquitectónicos corresponden a cimentaciones o bases de recintos circulares hechas de lajas paradas en doble hilada como para sostener paredes de quincha. Las evidencias fueron registradas por Walter López Córdova en 2007.

Iraqata. Asentamiento de carácter aldeano perteneciente al periodo Formativo dispuesto en una ladera del cerro Cabrapata sobre el camino que une a los barrios de Piladucho, la Unión y Santa Ana. El sitio fue excavado por Raúl Mancilla Mantilla en 1991 quien informa de un conjunto de recintos circulares con pisos, restos de enlucidos, entierros y ofrendas con cerámica relacionado con los conocidos estilos: Wichapana, Qarqampata, Rancha, Chupas, Kichkapata, etc. (Fig 23).

Piladucho. Restos de terrazas, canales y caminos cercanos a fuentes de agua y reservorios de la época prehispánica en la quebrada piladucho desde donde se unen dos riachuelos que forman la quebrada hasta el barrio la Unión. Las terrazas parecen corresponder a la época de los asentamientos de Iraqata y Qarqampata, mientras que los canales y reservorios forma, parte de un sistema de captación y distribución de agua durante la época colonial de la ciudad de Huamanga, el camino es sin prehispánico, conecta con poblados de las partes altas y bajas del valle de Huamanga.

La Unión. Restos de terrazas agrícolas asociadas con ofrendas de cerámica de la época Inca encontrados en el terreno propiedad de don Samuel Huancahuari, barrio La Unión próximo a la confluencia de las quebradas Piladucho y la Unión en el puente Sotocchaca. En la superficie de chacras y espacios no alterados hay también fragmentos de cerámica de los periodos Formativo, Huarpa y Wari.

Figura 23. Restos de enlucido con estrías que indican la presencia de estructuras de quincha.

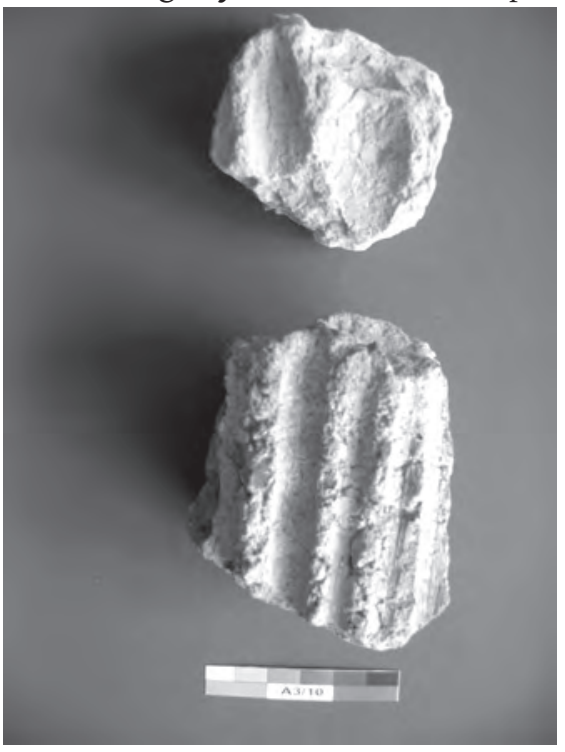


Santa Ana. Antiguo barrio de Santa Ana construido sobre los restos de ocupación cultural que viene desde el periodo Formativo, reocupado por las culturas Huarpa y Wari, según evidencias encontradas durante el proceso de remoción del terreno para el mejoramiento de la plaza, donde logramos rescatar 5 tumbas, 2 con estructura de cantos rodados y 3 en simple pozo excavado baja roca madre, todas de forma cilíndrica asociadas con cerámica e instrumentos de producción de cerámica de la época Wari, cuyos restos se extienden en el área que ocupa la plaza y viviendas adjuntas.

Waychaupampa. Promontorio ubicado entre la quebrada andamarca y el río Alameda. El sitio si bien está alterado por la construcción de viviendas modernas, en cuyos muros de adobe y tapial y espacios abiertos hay abundante material lítico y cerámica de los periodos Formativo, Huarpa y Wari (Fig.24 y 24a). Destacan algunos fragmentos incisos y pintados como los estilo torrecitas de Chavín y otros de pasta fina con bordes biselados al interior, a los que Cabrera (1991) los a denominado estilo Caja Huamanga por su parecido con la cerámica Caja Huancavelica. Este sitio esta propendo a desaparecer por el acelerado crecimiento suburbano.
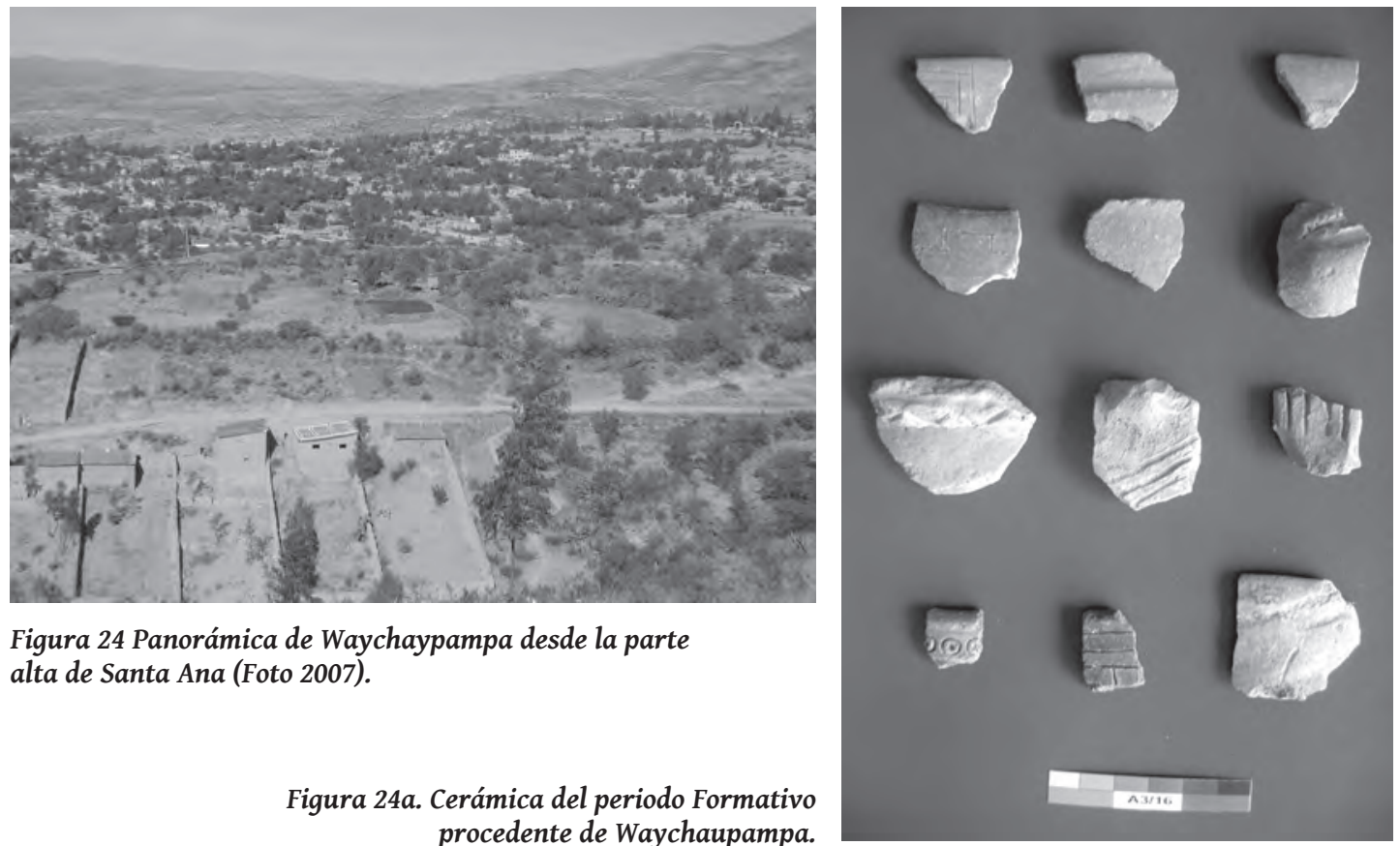

Figura 24 Panorámica de Waychaypampa desde la parte alta de Santa Ana (Foto 2007).

Figura 24a. Cerámica del periodo Formativo procedente de Waychaupampa.

Tinajeras.- Asentamiento de carácter aldeano localizado en la margen derecha superior de la quebrada Tinajeras al noroeste de la colina de Ñawimpuquio, el sitio contiene fragmentos de cerámica de los periodos Formativo, Huarpa y Wari, en las inmediaciones existe restos de terrazas con cerámica de filiación formativa, donde Gudelia Machaca efectuó excavaciones en 1987, reportando el hallazgo de una vasija de base plana y cuerpo globular decorado con círculos impresos de claro estilo Kichkapata relacionada con la influencia de la cultura Chavín en el valle de Huamanga .

Ñawimpuquio. Centro poblado localizado en la cima de la colina del mismo nombre altura del km $4 \mathrm{ca}-$ rretera Ayacucho-Abancay, se caracteriza por presentar restos de una extensa población urbana de la época Huarpa con antecedentes locales desde el periodo Formativo Inicial y reocupado posteriormente por los Waris quienes debieron de introducir cambios aun cuando la formación urbana de estructuras cuadrangulares, rectangulares, circulares y en «D» estaban ya presentes en Huarpa. Fue explorado por González (1966) y excavado por Lumbreras (1974) cuyos resultados sirvieron de base para pensar que se trataba de la capital política y administrativa de la cultura que simboliza el primer desarrollo regional 
de Ayacucho (Fig. 25). Las excavaciones efectuadas posteriormente en el mismo sitio y alrededores por Machaca (1993 y 1997); Cabrera (1998); Leone (2000), confirman la presencia Huarpa con sus antecedentes locales y reocupación poshuarpa sin descartar la hipótesis planeada por Lumbreras.

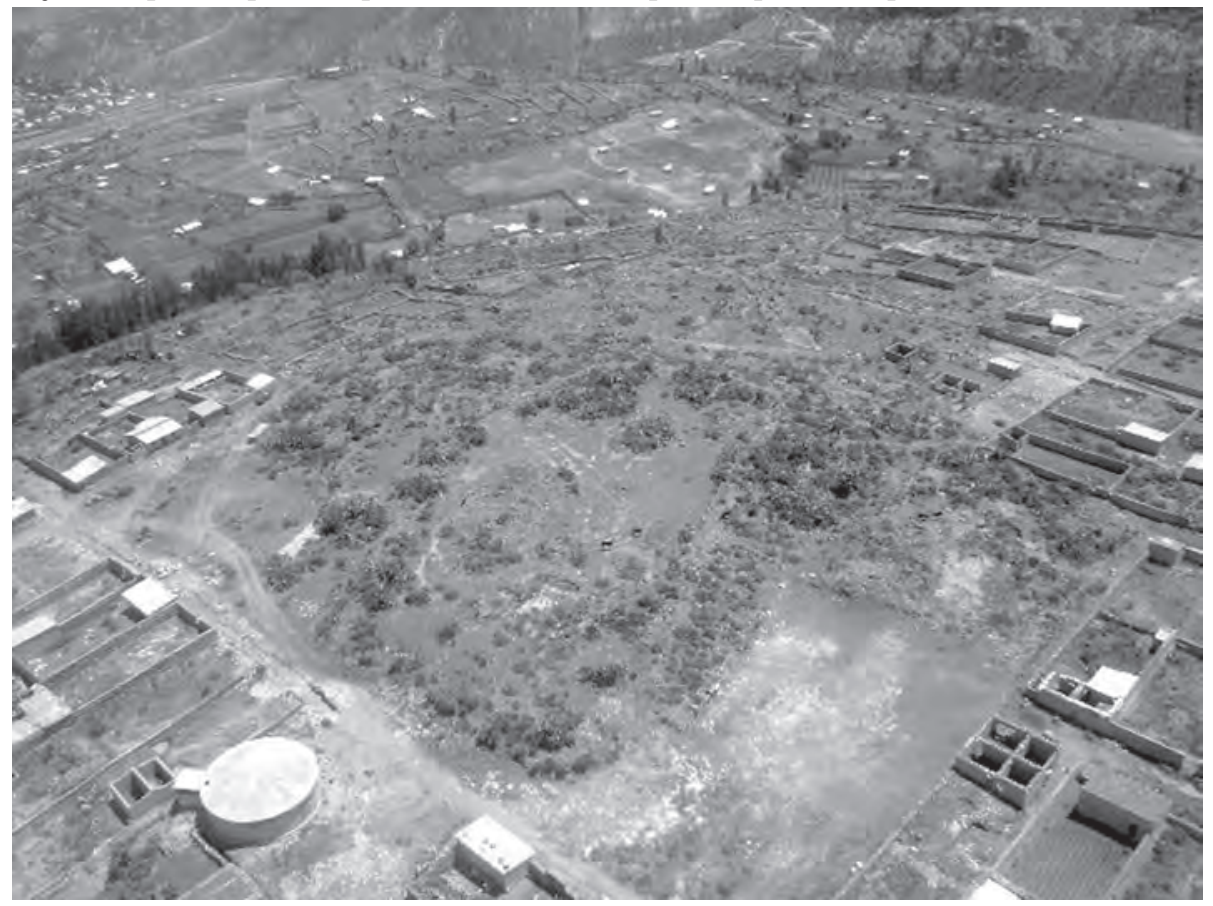

Figura 25. Asentamiento de Ñawimpuquio rodeado de viviendas modernas (Foto aérea 2010).

Ranraranrra. Zona pedregosa con petroglifos, ubicada a $1 \mathrm{~m}$ aproximadamente al oeste de la colina de Ñawimpuquio, el sitio fue documentado en la década del 30 del siglo XX por Pío Max Medina, posteriormente por Pérez et al. 2010, quines informan de la representación de figuras humanas con posibles trazos de serpientes, círculos y puntos en un afloramiento rocoso junto a un camino antiguo que va por la margen derecha de la misma quebrada Ñawimpuquio (Fig. 26). Estos restos culturales que corren el riesgo de desaparecer por el acelerado expansión suburbana y aprovechamiento de la piedra como cantera.

Lambrashuayqo. Restos de canal antiguo sobre el que se ha trazado el canal que abastecía de agua a la ciudad de Ayacucho

Figura 26. Figuras humanas en los petroglifos den Ranraranrra.

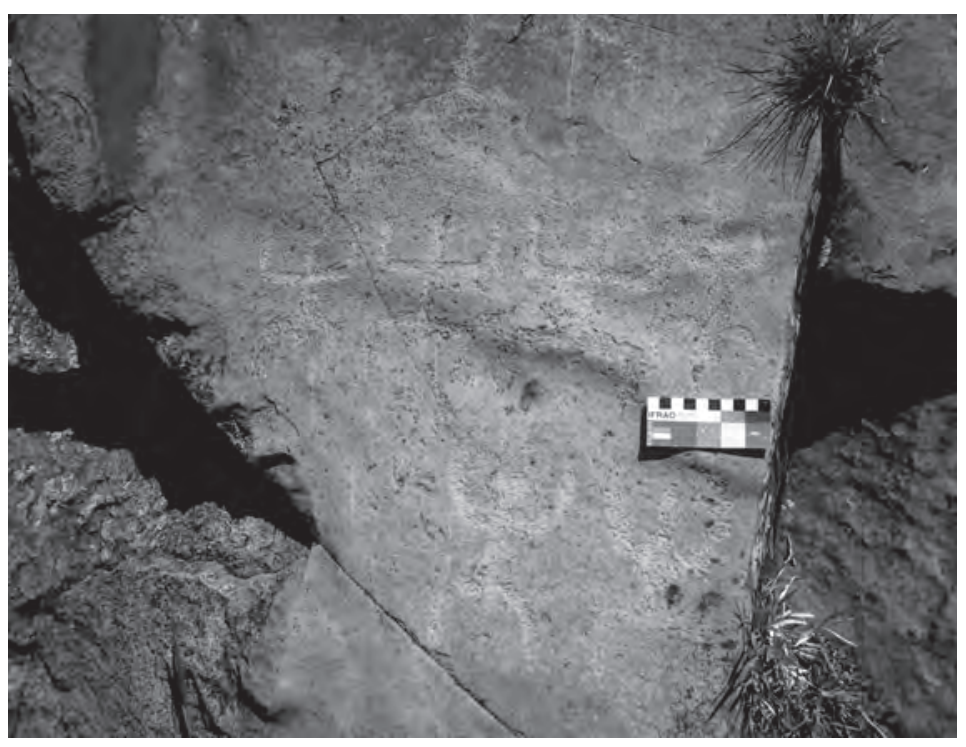


Figura 27. Huanta instalada en el ángulo noroeste de la plataforma superior del templo ceremonial de Chupas.

hasta por lo menos dos décadas atrás, las evidencias se encuentran en la margen izquierda de la quebrada Lambrashuayqo, sobre la carretera que corta parte del complejo ceremonial de Chupas.

Chupas. Complejo ceremonial en el que destaca el montículo central conocido como Ushno Era / Solar Moqo, constituido por tres plataformas superpuestas, visto a manera de ushno (Fig. 27), el sitio fue excavado por Cruzzat (1966) y Lumbreras (1974), quienes dan a conocer que se trataría de una estructura de carácter ceremonial con cerámica de estilo Kichapata o de influencia Chavín.

Cueva Chupas. Asentamiento precerámica, ubicado en el lado sureste del complejo ceremonial Chupas, que excavada por Robert K Vierra en 1971 como parte del proyecto Arqueológico Botánico Ayacucho- Huanta dirigido por Mac Neish. Se trata de un asentamiento cerrado con una ocupación cultural continua desde la fase Piki

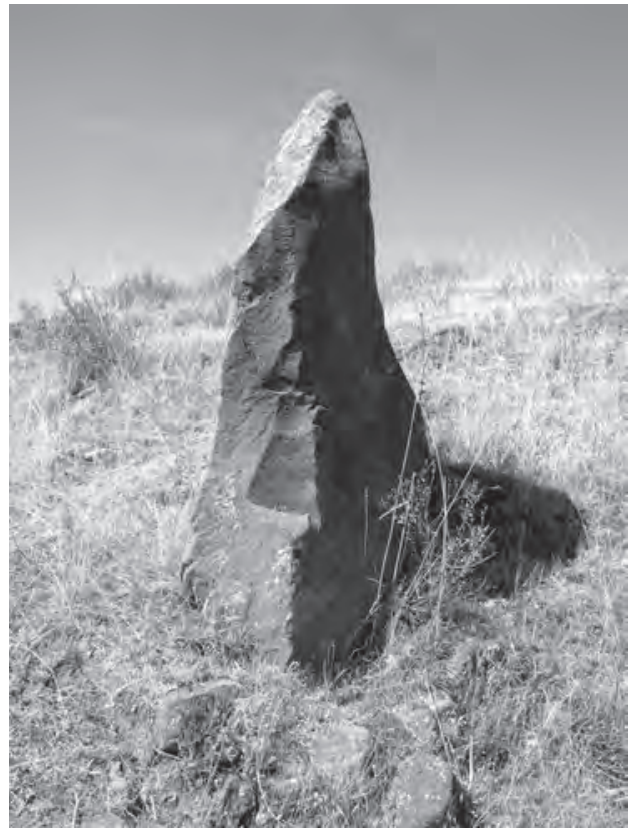
(5400 a.C.) hasta la época Wari (900 d.C.), de suma importancia para entender y explicar el cambio del Preceramico al sedentarismo.

Ayamachay. Pintura rupestre en la cara frontal de un abrigo rocoso en la parte de la comunidad de Ichubamba, Los motivos son figuras realistas de camélidos en actitud e movimiento como si estuvieran corriendo uno tras de otro están pintadas de color rojo oxido en gran parte tapadas con una capa de humo originados por la actividad domestica temporal que existe en la cueva y al parecer cubre a otras representaciones pictóricas.

Pukaorqo. Alineamientos de muros de contención dispuestos en la cima del cerro Pukaorqo, al este de Sacsamarca y próximo a canteras de arcilla color marón de fácil extracción. La cima contiene fragmentos de las épocas Huarpa y Wari.

Qachisqo. Asentamiento poblacional ubicado en cima del cerero Qachisqo al suroeste de Sacsamarca por donde se accede a través de un camino en zig zag, la cima tiene rastros de haber sufrido fuertes derrumbes en el lado oriental, habiendo quedado solo una parte de la cima con declive hacia el lado occidental donde se percibe restos de estructuras con abundantes fragmentos de cerámica y artefactos líticos en medio chacras, la cerámica pertenece a los periodos Formativo, Huarpa, Wari y Chanka. Fue registrado por Lumbreras (1974) como sitio de donde proviene el estilo Qachisqo de la cultura Chanka (Fig. 28).

Figura 28. Cerámica de estilos Chupas y Huarpa procedentes de Qachisqo

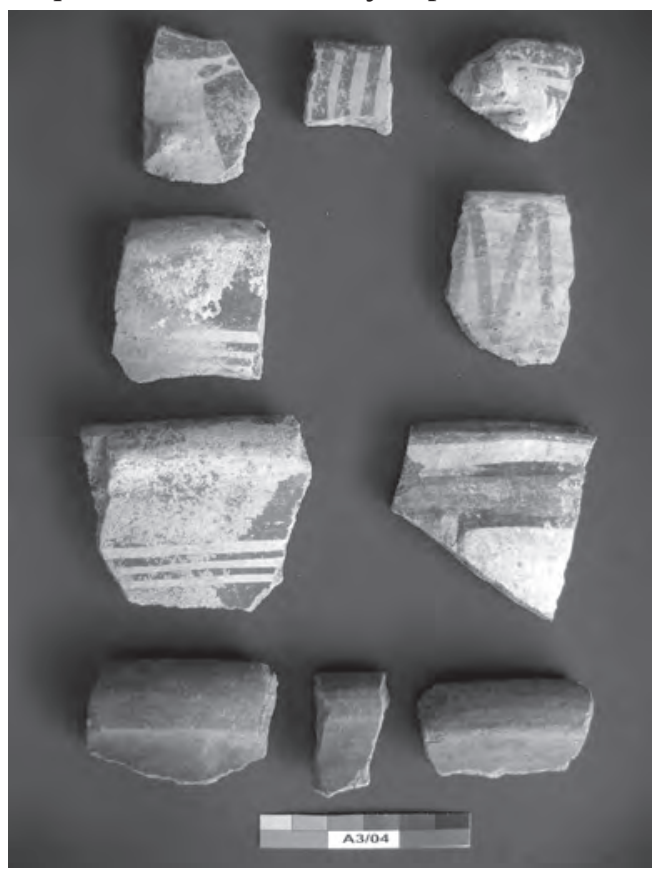




\section{Figura 29. Cerámica del periodo formativo superior (Rancha).}

Auquimarca. Fortificación Huarpa-Wari, ocupa la cresta de una alta y larga colina en las inmediaciones del centro poblado de Sacsamarca, desde donde se observa como un sitio inaccesible por las fuertes pendientes erosionadas que delimitan los lados oriental y occidental, en el lado sur existe restos de terrazas y de un probable camino de acceso a la cima, mientras que en el lado norte mantiene un declive natural compuesto por varios niveles naturales de terreno arcilloso que bajan hasta el borde del río Chillico. La cima de Auquimarca tiene por lo menos $1 \mathrm{~km}$ de largo por $40 \mathrm{~m}$ promedio de ancho, separado por lo menos con cuatro promontorios todos éstos con abundantes cerámica de filiación formativa, Huarpa, Wari y Chanka (Fig. 29).

Pijoy. Centro poblado Wari, ubicado en el lado sureste de Qorihuillcca Chico, se caracteriza por presentar abundantes fragmentos de cerámica, artefactos líticos y óseos esparcidos en chacras en la parte superior del

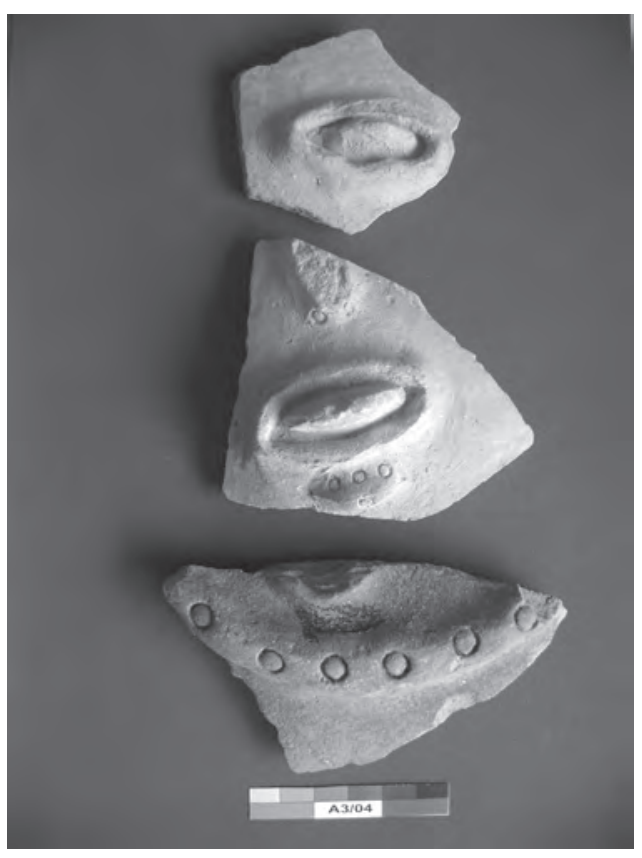
cerro Pijoy (Fig. 30). Presenta restos de viviendas establecidas en terrazas cuyas estructuras han sido destruidas con fines agrícolas, pero por la extensión de las evidencias se calcula que debió ser ocupada por una población no menor de 3000 habitantes.

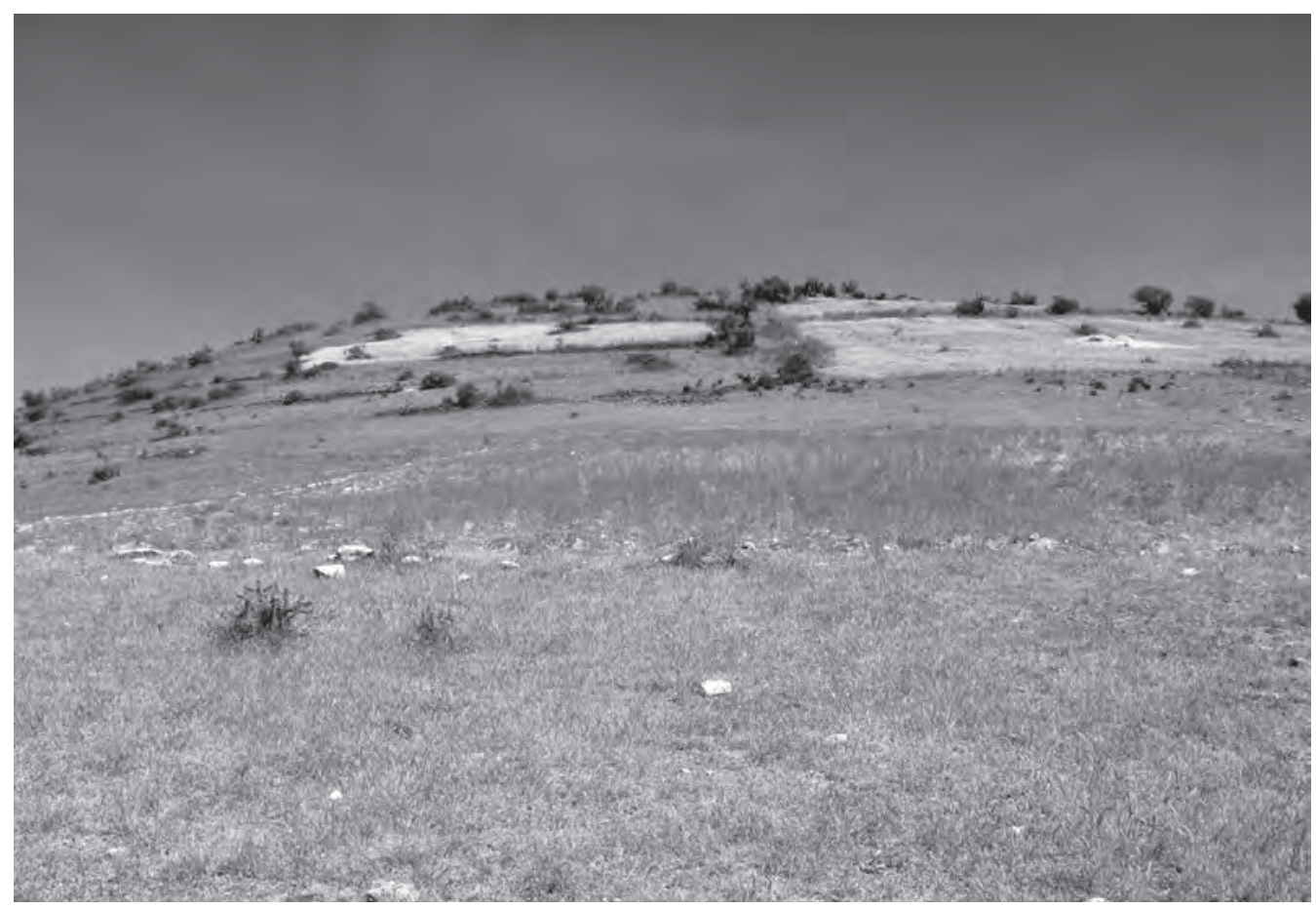

Figura 30. Poblado prehispánico de cerro Pijoy en Qorihuillcca. 
Picota. Cerro que rodea el lado oeste de la actual ciudad de Ayacucho, presenta afloramientos rocosos de lava volcánica con inclusiones de obsidiana en pequeñas bolas, además de arenas, arcillas y gravas que lo convierten en un terreno deleznable propenso a erosión fluvial y fenómenos geodinámicos que han originando deslizamientos, derrumbamientos, agrietamientos y una serie de quebradas con taludes verticales en la ladera oriental que desciende a la ciudad de Ayacucho y que en tiempos prehispánicos debió de afectar a los asentamientos de Aqo Wayqo, Maravillas, Soquiacato, etc. La cima presenta ligera inclinación de sur a norte y de oeste a este, en la superficie existe abundante material cultural como fragmentos de cerámica de los periodos Formativo (estilo Chocan), Huarpa y Wari, así como una variedad de asadas, que identifican a una población aldeana dedicada plenamente a la agricultura.

Kumunsenqa. Promontorio localizado en la margen derecha que da inicio al valle de Totorilla, barrio de magdalena área del actual centro ecológico recreacional y experimental «La Totorilla» de la Universidad Nacional de San Cristóbal de Huamanga (Fig. 31). La zona arqueológica a pesar de haber sido disturbada por la carretera, caminos de acceso e instalaciones de viviendas, aun contiene en cima abundantes fragmentos de cerámica Rancha, Huarpa y Wari en sus diferentes formas y estilos, tan igual que artefactos líticos. Los restos corresponden a una aldea típica de la cultura Huarpa, de donde procede la variedad de cerámica Huarpa conocida como Kumunsenqa, según Lumbreras $(1960,1974)$ que la exploró a fines de la década del 50 y primer lustro del 60.

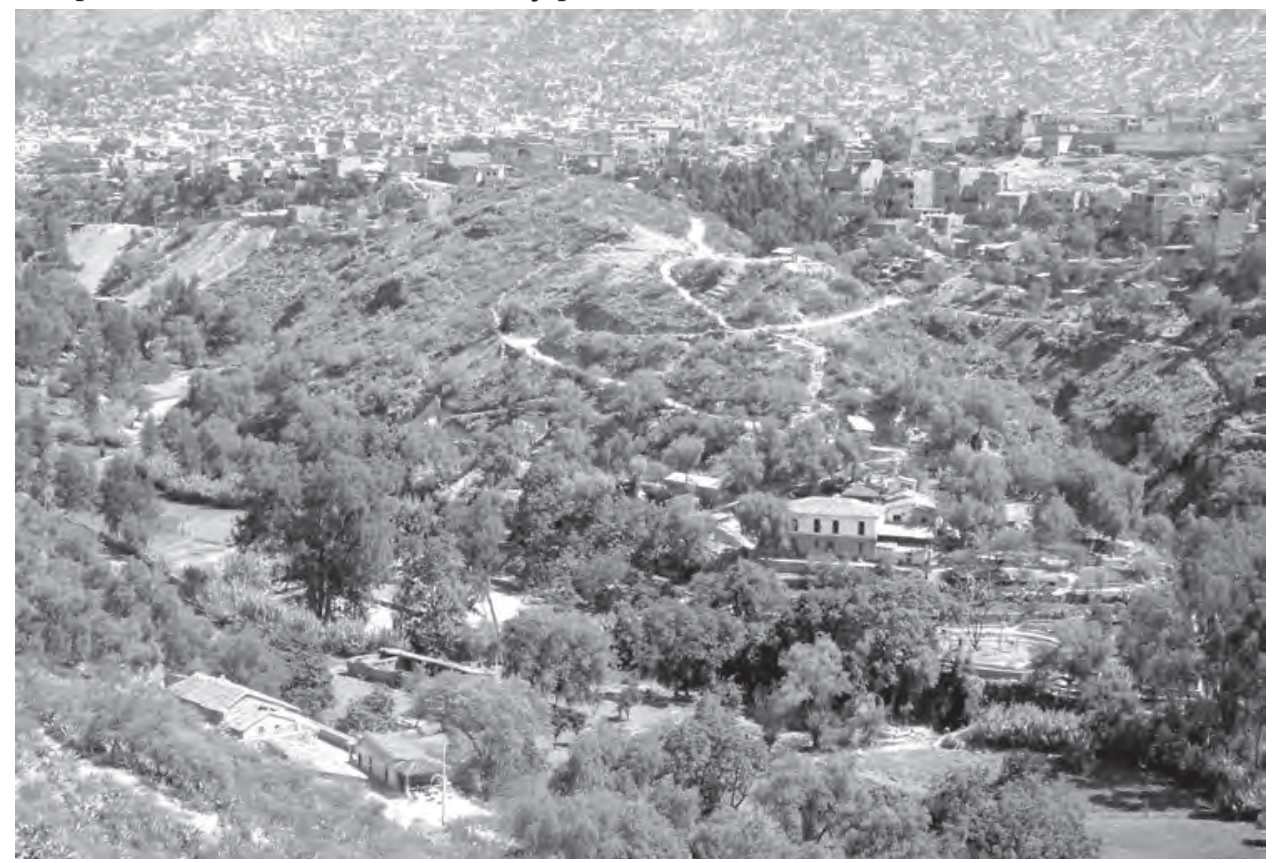

Figura 31. Panorámica de Kumunsenqa en Totorilla.

Totorilla B. Manantiales y canales de irrigación localizados ambos lados de la quebrada Totora, altura del fundo Totorilla de la UNSCH, lado derecho existe por lo menos cinco ojos de agua que filtra de la base de la meseta donde se encuentra ubicado el asentamiento arqueológico de Conchopata (Fig. 32). Estos afloramientos forman espacios húmedos con abundante vegetación ribereña compuesta por helechos, gramíneas y carrizos, y peces de agua dulce. Los canales están conectadas a diferentes niveles terrazas agrícolas, algunos están abandonados y otros reutilizados, uno de los canales del lado izquierdo está labrado en más de $100 \mathrm{~m}$ de distancia en la propia roca. 


\section{Figura 32 Manantiales que afloran en el lado} oriental de Conchopata.

Cielo Orqo. Situado en el extremo opuesto al sitio anterior, sobre los $4100 \mathrm{~m}$ de altitud, es una plataforma ceremonial construida en la cima del cerro Cielo Orqo altura del Km 52.5 carretera Ayacucho-Abancay. Se caracteriza por estar orientado al sur del eje cardinal de la ciudad de Wari (Fig. 33), desde donde se vislumbra como punto de conexión en la cabecera de cuencas de los ríos Huarpa y Pampas, está rodeado de manantiales y abrigos rocosos y en las inmediaciones hay cue-

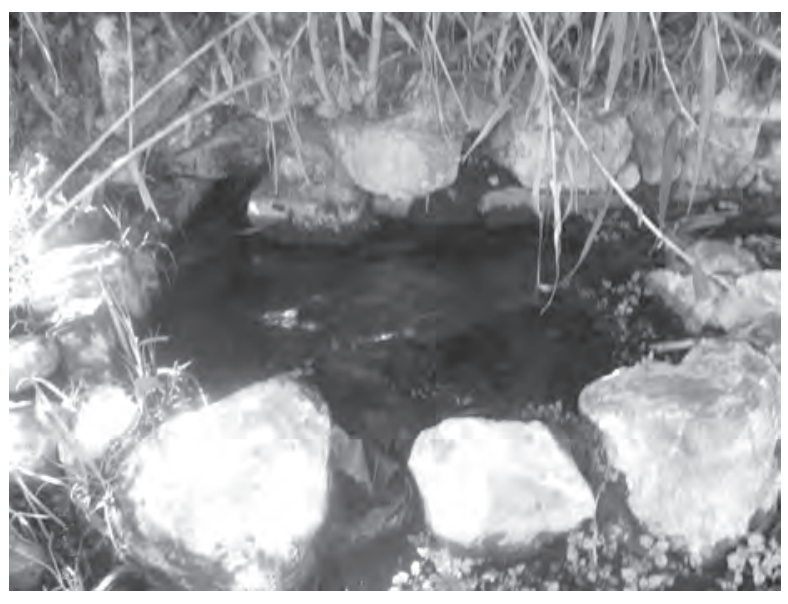
vas con pintura rupestre, que sirven de sustento para sostener en las actividades de ritos y ceremonias vinculados con la producción ganadera, agrícola y aprovechamiento de recursos naturales.

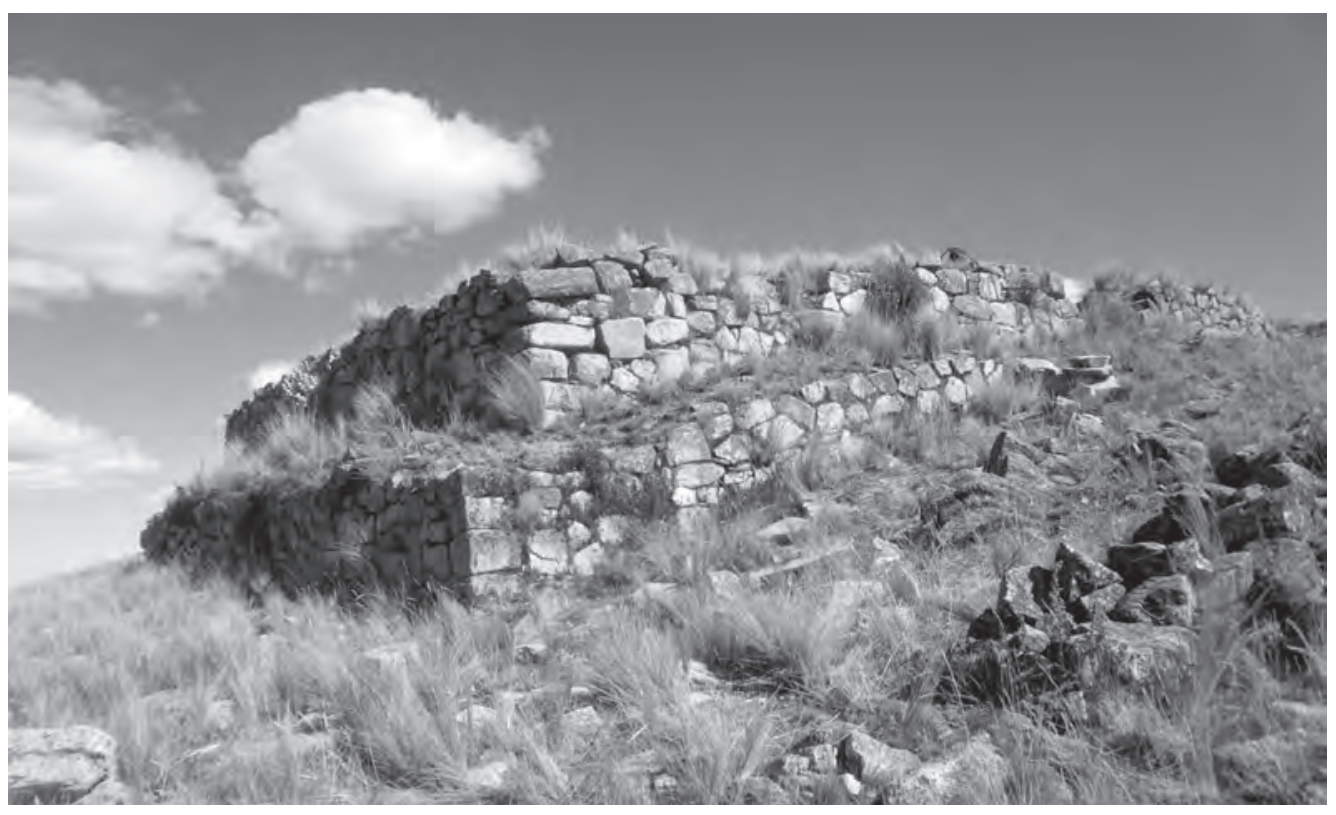

Figura 33. Angulo noreste del ushno de Cielo Orqo.

\section{DiscUSIÓN}

Los fechados de C14 que se presentan corresponden al Proyecto Arqueológico Botánico Ayacucho Huanta, dirigido por Richard Mac Neish entre 1969 y 1971. El asentamiento más antiguo de la periferia de Conchopata es sin duda las cuevas Puente que consisten en dos pequeñas cuevas o abrigos rocosos de lava volcánica, localizados a $\mathrm{Km} 4$ al norte de la ciudad de Ayacucho, tiene una secuencia cultural, desde por lo menos los 7500 a.C. hasta los 1750 a.C.), con una estratigrafía constituida por catorce capas y 43 ocupaciones, de las cuales la capa más profunda corresponde a la fase puente, las cuatro siguientes a fase Jaywa (7100 - 5800 a.C.), continuando 8 capas de la fase La fase Piki (5800-4400 a.C.). 10 capas de la fase Chihua (4400-3100 a.C.), y siete capas de la fase Cachi (3100 a 1750 a.C.) para culminar con la introducción de la cerámica en la fase Andamarca. 
La fase Andamarca, abarca desde 1750 a 1250 a.C., fechado con muestras procedentes de Wichqana, y Chupas, representa la introducción y dispersión de la cerámica en el valle de Huamanga y Huanta, cuenta con una decena de asentamientos de carácter aldeano, centros ceremoniales y cuevas ubicados entre la región de la puna y parte baja del valle, donde sus pobladores iniciaron a desarrollaron la agricultura en terrazas de cultivo temporal e intensivo, algunas irrigadas desde reservorios para sembríos de papa en las alturas, maíz en la parte media y zapallo en la parte baja del valle.

La fase Wichqana, enmarcada entre 1250 a 900 a.C. está sustenta con muestras procedentes del mismo sitio de Wichaqana, Jaywamachay, Tambillo, Ruyru Rumi, Solar Moqo (Usno Era) y Rayay Pampa. Tiene más de treinta sitios, entre aldeas, cuevas, centros ceremoniales, terrazas, etc. Localizadas en los valles de Huatatas, Totorilla, Pongora, Cachimayo, y en las inmediaciones de Luricocha, Huanta, Acosvinchos, Tambillo, y otros en las alturas de Quinua y Chiara. La fase Wichqana aparece asociada con de tipo Kichkapata de clara influencia Chavinoide, y los sitios aparecen distribuidos alrededor de centros ceremoniales con estructuras troncopiramidales ubicados en lugares estratégicos para el aprovechamiento de recursos, alrededor de amplios espacios abiertos o plazas asociados con estructuras circulares y en forma de $\mathrm{D}$, además de un sistema hidráulico que involucra el uso de canales controladas por la comunidad o centro aldeano.

Fase Chupas, con una antiguedad de 900 a 500 a.C. Respaldada con excavaciones Wichqana, Rajay Pampa, Ushno Pampa, Pikimachay y Rosamachay, a los que se incluye el registro de otros treinta asentamientos entre macrobandas, microbandas, villorrios, centros ceremoniales, aldeas porticadas, etc. muchas de estas distribuidas en el área que ocupa la actual ciudad de Wari y alrededores y en la misma ciudad de Ayacucho. La fase Chupas agrupa a cerámica tipos Kichkapata y Chupas, en esta última destaca el tipo negro inciso con superficie pulida, pasta fina con mica y ortosa; con formas de cuencos de paredes bajas y abiertas; el tipo Rojo sobre Negro, tiene pintura fugitiva de color rojo aplicada directamente sobre la superficie llana, con pasta y formas del mismo tipo que el negro inciso; las incisiones son cortantes y delgadas, con diseños a base de escalones y círculos impresos.

Fase Rancha, con materiales que datan de 500 a 200 a.C. se encuentra refrendada con muestras estratigráficas procedentes de Pikimachay, Jaywamachay, Rosamachay, Tambillo, Wichqana, Solar Moqo, y Tunasniyoc, además de más de cuarenta asentamientos entre microbandas, bandas, aldeas, centros ceremoniales. Centros administrativos, etc., explorados en la parte alta, media y baja de los valles de Ayacucho y Huanta. Ángel García Cook (citado por Lumbreras 1974: 90), señala que en las faldas del cerro Quicapata existen restos de andenerías, cisternas y canales de riego que pertenecerían a la época Rancha. La fase Rancha tiene como soporte los trabajos de Lumbreras $(1958,1974)$, en Aya Orqo, quien define una variedad de tipos, caracterizándose de manera general por ser delgada y fina; la pasta con partículas de cuarzo, mica y en algunos casos feldespato, en formas de platos, tacitas y cuencos con borde engrosado y plano; botellas y cántaros de cuello o pico corto y asas cintadas de bordes rectos. La cerámica Rancha comprende además una serie de sudivisiones como el Rancha pintado, Engobado Fino y Padrón Bruñido, todos emparentados a Paracas Necrópolis. A esto se incluye el tipo «Rojo Engobado» conocido con el nombre de «Chocán», cerámica que parece haberse iniciado desde las fases Chupas y Wichqana.

Fase Huarpa, tiene como antecedente las referencias de Julio C. Tello a raíz de su exploración en Tanta Orqo y Auki Willca 1931, luego en 1946, John Rowe, Donald Collier y Gordon Willey, formaron el grupo Huarpa con fragmentos decorados Negro sobre Blanco pero sin ubicación cronológica, sin embargo es Wendell C. Bennett quien encuentra cerámica Huarpa en niveles más profundos de una de sus excavaciones efectuadas en 1950; posteriormente Lumbreras (1960) y Menzel (1964, 1968), basados en criterios estilísticos la ubican como un estilo anterior a Wari, en sitios como Ñawimpuquio, Kumun Senga, Churukana, Tantawasi y Ancakwasi. Es el mismo tipo de cerámica encontrado en más de treinta sitios en las provincias de La Mar, Huanta y Huamanga en Ayacucho y Acobamba en Huancavelica, los que también fueron trabajados de manera tipológica sin validez cronológica (Benavides 1971). La 
fase Huarpa, propuesta por Mac Neish, cuenta con 128 sitios prospectados y excavados, con fechados radiocarbónicas de 200 a.C. a 200 d.C. de muestras recuperadas obtenidas en Solar Moqo (Usno Era) y Raqay Pampa, Ñawimpuquio, Conchopata y Lagunilla. Corresponde por tanto a la primera etapa de desarrollo regional de la cultura Ayacuchana o Huarpa y las etapas A,B y C de Lumbreras propuesta en 1969 y 1975 respectivamente. A lo que se incluye la cerámica de estilo Caja y Kumunsenqa. Una de las principales manifestaciones culturales Huarpa es sin duda la tecnología agraria, que tiene como fundamento las evidencias de canales y terrazas descubiertas en Chupas, Lagunilla y Ñawimpuquio, esta última considerada como posible capital política y administrativa.

Fase Ocros, según Mac Neish et. al, comprende de 200 a 700 d.C. y está respaldada con excavaciones en Ñawimpuquio, Lagunillas, Solar Moqo o ushno Era, Tunasniyoc, cuevas Tambillo, Chupas y Pikimachay, y más de sesenta sitios entre microbandas, macrobandas, aldeas ceremoniales, administrativas y fortificadas, terrazas, canales de irrigación, cuevas, abrigos, etc. dispersos en la microcuenca del Viñaca, complejo Wari, Tambillo, Ayacucho, Chiara, Huanta y Luricocha. Corresponde a la segunda etapa de desarrollo regional o fase Ayacucho (Lumbreras 1969) y a la fase D (Lumbreras 1974), que incluye al estilo Cruz Pata, con diseños de influencia Nasca expresado en tipos de Acuchimay, Totora y Tinajeras, así como la cerámica Huamanga y Conchopata. Las formas comunes corresponde a cántaros con cara gollete y apéndices de cabezas escultóricas, rostros humanos y de animales, e incluye una variedad de utensilios como cuencos, tazones, cucharones, cucharas, y cucharillas. Ocros es la fase en que según Mac Neish el estado regional ayacuchano adopta un carácter imperial, con la fundación de ciudades-estado rodeadas de numerosos caseríos, sitios menores y con un patrón de entierra de posibles reyes o elite gobernante.

Fase Wari o periodo de apogeo y expansión territorial del imperio Wari desarrollada entre los 700 a 900 d.C. época en la que evidentemente la población aumentó, de lo que solo se ha registrado cerca de cuarenta asentamientos entre centros urbanos, centros administrativos, caseríos, aldeas, microbandas y ciudad, con materiales analizados procedentes de la misma ciudad de Wari, Conchopata, Ñawimpuquio, Tunasniyoc y de las cuevas de Tambillo, Pikimachay, Ayamachay y Chupas, donde el componente cultural más significativo es la cerámica de los estilos Wari polícromo (Chakipampa), Robles Moqo B, Viñaque (Wari medio), Wari geométrico y Huamanguilla negro-sobre-blanco, con formas de vasijas de ollas, botellas con estribo, y grandes keros o cantaros decorados con motivos naturalistas, antropomórficos y zoomórficos sobre base roja o naranja.

Fase Huamanga, vinculada con el despoblamiento de la región de Ayacucho, a consecuencia de la caída del Imperio Wari, tiene cerca de 30 asentamientos localizados en las partes altas, medias y bajas del valle de Huamanga, data de los 900 a 1200 d.C. Comprende varios tipos de cerámica como el Wari geométrico que continua desde la fase anterior, y los nuevos tipos Huamanguilla, Huamanga, y Ramos Chayoc. Se trata de una fase tentativa que debe corroborarse con el dato estratigráfico tan igual que la fase Chanka. La fase Huamanga fue fechada con materiales de excavación procedentes de Conchopata, Tunasniyoc y de las cuevas de Pikimachay, Ayamachay, Tambillo y Chupas.

La fase Chanka, representa el final local de la secuencia de Ayacucho, aunque carácter hipotética, comprende desde los 1100 d.C. hasta el siglo XV, representada con 26 sitios entre microbandas, aldeas, fortificaciones, centros administrativos y terrazas. Localizados desde las partes elevadas de la cuenca hasta las parte bajas del valle de Huamanga, En esta fase se registra importantes cambios en el patrón de asentamiento, sistema de subsistencia, y en el uso de herramientas líticos, con poca evidencia encontrada en las excavaciones realizadas en Jaywamachay, Pikimachay, Ayamachay y Tambillo, y asociada con cerámica de tipo Arqalla, con superficies llanas o brochadas con diseños incisos o aplicados y Aya Orgo con ollas de superficie brochada, ollas con decoración antropomórfica aplicada, y algunos con diseños marrón-negro sobre bases blancas que son similares a aquellos modernos de la cerámica Quinua negro sobre amarillo, a lo que se debe incluir el estilo Qachisqo y Tanta Orqo, comprende también cantidades de herramientas de roca en forma de morteros, porras, hachas en forma de $\mathrm{T}$, y azuelas. 
Y finalmente, la fase Inka que se refiere al tiempo que convivieron con los Chancas desde por lo menos 1470 hasta la fundación de la ciudad de Huamanga en 1,540, está representada con sitios de indudable modelo Incaico como el asentamiento de Condormarca en Humanguilla y algunos sitios con cerámica entre los que destaca la zona de Socos en la microcuenca del río Chillido.

\title{
CONCLUSIONES
}

Se cuenta con un registro de por lo menos 220 asentamientos en una extensión de paisaje geográfico equivalente a $400 \mathrm{~km}^{2}$ aproximadamente que tiene como centro el sitio de Conchopata.

El área de estudio fue subdividida en periferia noroeste, noreste, sureste y suroeste de los cuales la noreste contiene una mayor cantidad de asentamientos distribuidos en las microcuencas del Totorilla, Yucaes,Muyurina, Chaqo y Pongora.

El sitio más temprano o antiguo corresponde a la cueva Puente y el más tardío a la época Chanka con una antigüedad de 9000 a.C. y 1200 d.C. según fechado de radiocarbono del proyecto dirigido por Mac Neish.

Los restos encontrados corresponden a las categorías de centros poblados, cementerios, petroglifos, pintura rupestre, ushnos, caminos, canteras, qochas, reservorios, canales, terrazas, centros ceremoniales, fortificaciones, templos, espacios con cerámica y líticos, etc.

De un examen somero de las previas desarrolladas en el área del estudio sabemos que por lo menos 172 sitios corresponden a los trabajos del Proyecto Arqueológico Botánico Ayacucho-Huanta desarrollado por Mac Neish $(1981,1983)$ sobre la base de muchos de esto sitios y agregando algunos nuevos Mario Benavides Calle (1976) presenta unos 126 sitios. Ahora con el avance de estas dos fuentes se presenta una relación de 220 sitios.

\section{Agradecimientos}

En las salidas de campo participaron Noemí Cruz, Edith Verástegui, Alexander Chavarría y Edith Ortega. El plano que se adjunta fue elaborado con apoyo de Angélica Canchari y Edwar Perlacios Flores, a todos ellos hago mi sincero reconocimiento cuyo aporte constituye la base para hacer realidad el presente trabajo.

\section{BibliografíA}

\author{
ALARCóN, Marlene Mariscot \\ 1990 Olleros de la época Huari. Informe de prácticas. Facultad de Ciencias Sociales, Universidad Nacional \\ de San Cristóbal de Huamanga (UNSCH). \\ ALARCON GUTIERREZ, Edgar \\ 1999 Investigación Arqueológica en Qorihuilca Grande, Época Huari. Informe de prácticas pre-profesionales, \\ UNSCH.
}

BENNETT Wendell C.

1953 Excavations at Wari, Ayacucho, Perú. Publications in Anthropoloy, Numbers forty-nine and fifly. Yale university Press.

BENAVIDES CALLE, Mario

1976 Yacimientos Arqueológicos en Ayacucho. Ayacucho: Departamento Académico de Ciencias Histórico Sociales, UNSCH.

BERROCAL, Marcelina

1991 Estudio Arqueológico en Muyu Orqo, Ayacucho. Trabajo de Bachiller, UNSCH.

CABRERA ROMERO, Martha

1992 Investigaciones arqueológicas en Waychaupampa. Informe de prácticas pre-profesionales. Facultad de Ciencias Sociales, UNSCH. 
1998 Evaluación arqueológica en el complejo turístico de Ñawimpuquio. Informe presentado al INC, Ayacucho. CASAFRANCA, José

1960 «Los nuevos sitios arqueológicos chavinoides en el departamento de Ayacucho». Antiguo Perú, Espacio y Tiempo:325-334. Lima: Editorial Juan Mejía Baca.

CÁRDENAS RIVEROS, Marle Luz

1995 Excavaciones en el yacimiento arqueológico de San Miguel de Huamanga. Informe de prácticas pre-profesionales. Facultad de Ciencias Sociales, UNSCH.

CRUZATT, Augusto

1966 Excavaciones en Chupas, Ayacucho. Tesis de Bachiller, UNSCH.

DOI, Masaki

2002 Informe preliminar del proyecto de prospecciones arqueológicas en los valles de Ayacucho y Huanta, Perú.

FLORES, Isabel

1960 «Wichqana, sitio Temprano en Ayacucho». Antiguo Perú : Espacio y Tiempo: 335-244. Lima: Librería Juan Mejia Baca.

GONZÁLEZ CARRE, Enrique

1966 Investigación arqueológica en Ñawimpuquio. Consejo General de Investigaciones, UNSCH.

1972 «Exploraciones en Ñawimpuquio, Ayacucho». Arqueología y Sociedad. № 7-8. Lima: Museo de Arqueología y Etnología, UNMSM.

GONZÁLEZ CARRE, Enrique y José CAHUAS MASA

1980 El sitio Arqueológico de Kumunsenqa, Ayacucho. Dirección de Investigaciones, UNSCH.

HUAMÁN LIRA, Fredy

2006 Estudio arqueológico en Huancaqasa: un intento de reconstrucción de la época Huarpa. Trabajo de Licenciatura, Facultad de Ciencias Sociales, UNSCH.

ISBELL, William

1985 «El origen del Estado en el valle de Ayacucho». Revista Andina 3: 57-106. Cusco.

2001 «Repensando el Horizonte Medio: el caso de Conchopata, Ayacucho, Perú». Boletín de Arqueología PUCP, No. 4, 2000: 9-68. Huari y Tiwanaku: Modelos vs. Evidencias (Primera Parte) P. Kaulicke y W. Isbell (eds.). Lima: PUCP.

2009 «Conchopata: Paisaje urbano, identidad, producción artesanal en una ciudad del Horizonte Medio». Conchopata № 2: 13-58. I. Pérez y L. Valle (eds.), Escuela de Formación Profesional de Arqueología e Historia, Facultad de Ciencias Sociales, UNSCH.

LÓPEZ, Walter

1994 Excavaciones arqueológicas en Muyo Orqo, temporada 1993-94. Informe de prácticas pre-profesionales, UNSCH.

LUMBRERAS, Luis

1958 «Estudio de la cerámica de Aya Orqo». Anuario de Museo Histórico Regional de Ayacucho. №9: 27-35.

1959 «Sobre los Chancas». Actas del II Congreso Nacional de Historia del Perú. Tomo I: 211-242. Lima.

1969 De los Pueblos, las culturas y las artes del antiguo Perú. Lima: Moncloa Campodónico.

1974 Las Fundaciones de Huamanga, hacia una prehistoria de Ayacucho. Lima: Editorial Nueva Educación.

2010 Plan de Manejo del Complejo Arqueológico Wari. Gobierno Regional, Ayacucho.

LEONE, Juan

2002 Excavaciones en Ñawimpuquio, Ayacucho 2001. Informe presentado al INC, Lima.

MENZEL, Dorothy

1968 La Cultura Huari. Lima: Compañia de Seguros Peruano- Suiza.

MANCILLA, Raúl

2008 Iraqata: sitio de la época Formativa en Ayacucho. Tesis de Licenciatura, UNSCH.

MACHACA; Gudelia

1991 Investigaciones arqueológicas en Ñawimpuquio. Tesis de Bachiller, UNSCH.

1997 Secuencia Cultural y nuevas evidencias de formación urbana en Ñawimpuquio. Tesis de Licenciatura, Facultad de Ciencias Sociales, UNSCH. 
MACNEISH, Richard; Ángel GARCÍA; Luis G. LUMBRERAS; Robert VIERRA y Antoinette NELKEN-TENER

1981 Prehistory of the Ayacucho basin, Perú. Excavations and Chronology. Vol. II. The University of Michigan Press.

MACNEISH, Richard; Robert VIERRA; Antoinette NELKEN - TENER; Rochelle LURIE y Ángel GARCÍA

1983 Prehistory of the Ayacucho Basin, Perú. Volume IV The Preceramic way of Life. The University of Michigan Press.

MARROQUIN LARREA, Oswaldo

2001 Reconocimiento de sitios arqueológicos en Huascahura, Ayacucho. Informe de Practica Pre Profesional, Facultad de Ciencias Sociales, UNSCH.

OCHATOMA, José

1985 Jargampata de Huamanga investigaciones arqueológicas en un yacimiento correspondiente al Horizonte Temprano. Tesis de Bachiller. UNSCH.

1986 Acerca del Formativo en la sierra Centro- Sur. Tesis. Licenciatura. UNSCH.

1987 Aqo Wayqo poblado rural de la época Huari. Lima: CONCYTEC.

2007 Alfareros del Imperio Huari, vida cotidiana y áreas de actividad en Conchopata. Facultad de Ciencias Sociales, UNSCH.

OCHATOMA, José y Martha CABRERA

2001 Poblados rurales Huari, una visión desde Ayacucho. Facultad de Ciencias Sociales, UNSCH.

OCHATOMA, José, Antonio PARIHUAMAN y Ulises LARREA

1984 «Cupisnique en Ayacucho?». Gaceta Arqueológica 9: 10. INDEA.

ORTEGA HUAYAPA, Edith

2006 Prospección arqueológica entre el espacio comprendido Entre las Quebradas Carimayo y Lambrashuayqo, Informe de Práctica Pre- Profesional, Facultad de Ciencias Sociales, UNSCH.

POZZI-ESCOT, Denise

1982 Proyecto Qonchopata: Campaña 1982. Instituto Nacional de Cultura. Ayacucho.

1985 «Conchopata un poblado de especialistas durante el Horizonte Medio». Boletín del Instituto Francés de Estudios Arqueológicos Andinos 14 (3-4): 115-129, Lima: IFEA.

2001 «Viejas formas, nuevos estilos: la Tradición del barro». En: Huari Arte Precolombino peruano, Pp. 273. 306, colección América, Centro Cultural el Monte.

2009 «Conchopata una comunidad de ceramistas». Conchopata № 2:57-78, I. Pérez y L. Valle (eds.), Escuela de Formación Profesional de Arqueología e Historia, Facultad de Ciencias Sociales, UNSCH.

PÉREZ, Ismael

2003 Informe Final excavaciones de emergencia en Muyo Orqo. INC.

2004 «Indicadores de actividades alfareras en Muyo Orqo». Investigaciones en Ciencias Sociales. Pp. 47-74, Instituto de Investigación de la facultad de Ciencias Sociales, UNSCH.

PÉREZ CALDERÓN, Ismael, y José OCHATOMA

1998 «Viviendas, Talleres, y Hornos de Producción Alfarera Huari en Conchopata». Conchopata: Revista de Arqueología 1: 72-92, Oficina de Investigación, UNSCH.

ROWE , John; Donald COLLIER y Gordon WILLEY

1949 «Reconnaissance notes of the site of Huari, near Ayacucho Perú». American Antiquity, vol. XV, № 2: 120-137. Menasha: Society for American Archaeology.

TELLO, Julio C.

1979 «Las ruinas de Wari». En: R. Ravines (comp.) Cien Años de de Arqueología. Petróleos del Perú (ed.) Reproducción del original publicado en el diario el Perú el 27 de agosto, Lima.

TAPAHUASCO SULCA,Regina

1993 San Miguel de Ayacucho, un asentamiento arqueológico de la época Wari. Informe de práctica pre-profesional, facultad de Ciencias Sociales, UNSCH.

VERASTEGUI ARANGO, Edith

2009 Prospección arqueológica en la microcuenca de del río Chillico, Ayacucho. Informe de práctica pre-profesional, Facultad de Ciencias Sociales, UNSCH. 